\title{
A novel human Smad4 mutation is involved in papillary thyroid carcinoma progression
}

\author{
Sonia D'Inzeo ${ }^{1}$, Arianna Nicolussi ${ }^{1}$, Caterina Francesca Donini, \\ Massimo Zani ${ }^{2}$, Patrizia Mancini ${ }^{1}$, Francesco Nardi ${ }^{1,3}$ and Anna Coppa ${ }^{1}$
}

Departments of ${ }^{1}$ Experimental Medicine, ${ }^{2}$ Molecular Medicine and ${ }^{3}$ Radiological Sciences, Oncology and Anatomical Pathology, Sapienza University of Rome, Viale Regina Elena 324, 00161 Rome, Italy

(Correspondence should be addressed to A Coppa; Email: anna.coppa@uniroma1.it)

\begin{abstract}
Smad proteins are the key effectors of the transforming growth factor $\beta$ (TGF $\beta$ ) signaling pathway in mammalian cells. Smad4 plays an important role in human physiology, and its mutations were found with high frequency in wide range of human cancer. In this study, we have functionally characterized Smad4 C324Y mutation, isolated from a nodal metastasis of papillary thyroid carcinoma. We demonstrated that the stable expression of Smad4 C324Y in FRTL-5 cells caused a significant activation of TGF $\beta$ signaling, responsible for the acquisition of transformed phenotype and invasive behavior. The coexpression of Smad4 C324Y with Smad4 wild-type determined an increase of homo-oligomerization of Smad4 with receptor-regulated Smads and a lengthening of nuclear localization. FRTL-5 clones overexpressing Smad4 C324Y showed a strong reduction of response to antiproliferative action of TGF $\beta 1$, acquired the ability to grow in anchorageindependent conditions, showed a fibroblast-like appearance and a strong reduction of the level of E-cadherin, one crucial event of the epithelial-mesenchymal transition process. The acquisition of a mesenchymal phenotype gave the characteristics of increased cellular motility and a significant reduction in adhesion to substrates such as fibronectin and laminin. Overall, our results demonstrate that the Smad4 C324Y mutation plays an important role in thyroid carcinogenesis and can be considered as a new prognostic and therapeutic target for thyroid cancer.
\end{abstract}

Endocrine-Related Cancer (2012) 19 39-55

\section{Introduction}

Smad4 is a key signal transducer of the transforming growth factor $\beta$ (TGF $\beta$ ) superfamily that controls a broad range of cellular processes ranging from proliferation to differentiation and apoptosis (Heldin et al. 1997, Massagué 1998). TGF $\beta$ ligands bind to heterotetrameric complexes of receptors with serinethreonine kinase activity, leading to an increase in their ability to phosphorylate receptor-regulated Smads (R-Smads). The phosphorylation of R-Smads (Smad2 and Smad3) by the type 1 TGF $\beta$ receptor induces their oligomerization with Smad4, which represents the only mammalian common mediator of TGF $\beta$ signaling. The Smad2/3-Smad4 complexes translocate to the nucleus, where they bind to the promoters of target genes, activating or repressing their transcription (Massagué et al. 2005, Massagué \& Gomis 2006).
Smad proteins show a tripartite structural organization, and three main domains have been recognized: Mad homology 1 (MH1), MH2, and an interposed linker region (Shi 2001). MH1 domain has an intrinsic binding activity to DNA sequences, whereas $\mathrm{MH} 2$ is important for homo- and heteromeric complex formation, together with transcriptional activation and repression (Wotton et al. 1999).

Deregulations of TGF $\beta$ signaling are central to tumorigenesis and tumor progression through their effects on cellular processes, including proliferation and cell invasion (Blobe et al. 2000, Ikushima \& Miyazono 2010). Absence of or decreased SMAD4 expression has been found in various cancers, including pancreatic, colorectal, head and neck (Bornstein et al. 2009, Ikushima \& Miyazono 2010), and more recently found in papillary thyroid 
carcinomas (D'Inzeo et al. 2010). These results provide evidence that the TGF $\beta$ signaling pathway functions as a tumor suppressor that cancers must bypass for their progression. On the other hand, TGF $\beta$ can exhibit tumor-promoting function as demonstrated in prostate and skin cancer progression (Wikström et al. 1998, Padua \& Massagué 2009). A tumor-promoting action of TGF $\beta$ has also been demonstrated in papillary thyroid carcinomas, where the concomitant presence of BRAF V600E mutation determined a reduction in sodium iodide symporter expression and an increase of TGF $\beta$ secretion, suggesting that hyperactivation of TGF $\beta$ signaling is responsible for the pro-tumorigenic activity (Riesco-Eizaguirre et al. 2009).

Smad4 mutations have been found at high frequency in a representative group of sporadic thyroid neoplasms (Lazzereschi et al. 2005), although the presence of mutational hotspots has not been identified, as described for gastrointestinal or pancreatic cancer (Iacobuzio-Donahue et al. 2004).

In this work, we study the effect of Smad4 mutations isolated from papillary thyroid carcinomas and nodal metastasis (Lazzereschi et al. 2005) and stably expressed in FRTL-5 cells, widely used as a normal control (Pang et al. 1989, Shimura et al. 2001, Pomérance et al. 2006, Visconti et al. 2007, Kogai et al. 2008). Mutations A226T, N263S arise in the linker region, while the $\mathrm{C} 324 \mathrm{Y}$ and $\mathrm{P} 550 \mathrm{~S}$ mutations arise in the MH2 domain of the protein. Most of Smad4 gene mutations in human cancer are missense, nonsense, and frameshift mutations at the MH2 domain, which interfere with the homo-oligomer formation of Smad4 protein and hetero-oligomer formation between Smad4 and R-Smad proteins (Miyaki et al. 1999, Iacobuzio-Donahue et al. 2004).

The aim of our study was to describe the effect of a new mutation of Smad4, Smad4 C324Y, isolated from nodal metastases of papillary thyroid carcinoma. Thyroid cells, stable expressing this mutation, showed a significant increase of TGF $\beta$ signaling responsible for the acquisition of transformed phenotype and invasive behavior.

\section{Materials and methods}

\section{Reagents and constructs}

DMEM, Coon's modified Ham's F-12 medium, PBS, fetal bovine serum, trypsin-EDTA, L-glutamine $100 \times$ $(200 \mathrm{mM})$, and the six-hormone mixture $(6 \mathrm{H})$ containing TSH $(10 \mathrm{mU} / \mathrm{ml})$, insulin $(10 \mu \mathrm{g} / \mathrm{ml})$, hydrocortisone $\left(10^{-8} \mathrm{M}\right)$, transferrin $(5 \mu \mathrm{g} / \mathrm{ml})$, glycyl-L-histidyl-L-lysine acetate $(10 \mathrm{ng} / \mathrm{ml})$, and somatostatin $(10 \mu \mathrm{g} / \mathrm{ml})$ were purchased from SigmaAldrich Co.

The human recombinant TGF $\beta 1$ isoform was purchased from Peprotech (Rocky Hill, NJ, USA).

Phenylmethylsulfonyl fluoride (PMSF), protease cocktail inhibitor containing $1 \mathrm{mg} / \mathrm{ml}$ leupeptin, $2.5 \mathrm{mg} / \mathrm{ml}$ aprotinin, and $1 \mathrm{mg} / \mathrm{ml}$ benzamide hydrochloride, and phosphatase inhibitor cocktail were purchased from Sigma-Aldrich Co.

Antibodies to green fluorescent protein (GFP FL), $\mathrm{N}$-cadherin (H63), HA (Y11), and $\beta$-actin (C4) were obtained from Santa Cruz Biotechnology (Santa Cruz, CA, USA). Antibodies to the phosphorylated form of Smad2 (P-Smad2) were purchased from Cell Signaling Technology (Beverly, MA, USA), E-cadherin was from Immunological Sciences (Rome, Italy), Smad2/3 from BD Biosciences PharMingen (San Diego, CA, USA), and GAPDH and cAMP response element-binding (CREB) were from Abcam. Texas-red-conjugated goat anti-mouse IgG was obtained from Jackson Laboratories (Bar Harbor, ME, USA) and HRP-conjugated secondary antibodies were purchased from Sigma-Aldrich Co.

Transfections were performed by lipofectin kit provided by Lipofectamine Plus (Gibco/BRL Life Technologies) and stable clones were obtained by selection with geneticin G418 (Invitrogen Life Technologies).

GFP-tagged Smad4 constructs were obtained subcloning the human SMAD4 gene in Clontech pEGFPC3 vector, which allows in frame fusion to the $\mathrm{C}$-terminus of GFP. pCMV5 3TP-Lux, pCMV5- $\beta$ Gal, pCMV5 HA-Smad4 wild-type (wt), and pCMV5 FLAG-Smad2 wt were kindly provided by Prof. Liliana Attisano.

\section{Site-directed mutagenesis, subcloning, and stable transfectants}

Site-directed mutagenesis was used to introduce missense mutations into the human Smad4 cDNA wt inserted in a pcDNA3 plasmid. The mutants A226T, N263S, C324Y, and P550S were constructed by PCR using the QuikChange site-directed mutagenesis kit from Stratagene (La Jolla, CA, USA) according to the manufacturer's protocol. Mutations were introduced using the following primers: COD A226T forward 5'-CTTCCACAAGTCAGCCTACCAGTATA CTGGGGGGC- $3^{\prime}$ and COD A226T reverse 5'-GCCCCCCAGTATACTGGTAGGCTGACTTGT GGAAG-3'; COD N263S forward 5'-GCTACTTACCATCATAGCAGCACTACCACCTGG-3' and COD N263S reverse 5'-CCAGGTGGTAGTGCTGCTATGATGGTAAGTAGC-3'; COD C324Y forward 5'-CCTGCTCCTGAGTATTGGTATTCCATTGCTTACTTTG- $3^{\prime}$ and 
COD C324Y reverse 5'-CAAAGTAAGCAATGGAATACCAATACTCAGGAGCAGG-3'; COD P550S forward 5'-CCATGCCGATTGCAGACCCACAATCTTTAGACTGAGGTCTTTTAC- $3^{\prime}$ and COD P550S reverse 5'-GTAAAAGACCTCAGTCTAAAGATTGTGGGTCTGCAATCGGCATGG- $3^{\prime}$. The Smad4 cDNA containing the mutations was selected by sequencing. The Smad4 cDNA wt or mutated was subcloned into the expression vector pEGFPC 3 , which allows in frame fusion to the C-terminus of the tag GFP (Clontech), by $5^{\prime}$-HindIII and $3^{\prime}$-EcoRI sites.

The resultant constructs were used to stable transfect FRTL-5 rat thyroid cells (American Type Culture Collection (ATCC) \#8305) by lipofectamine method as recommended by the manufacturer (Lipofectamine Plus, Gibco/BRL Life Technologies). FRTL-5 cells grown in $100 \mathrm{~mm}$ tissue culture dishes were transfected with $8 \mu \mathrm{g}$ vector pEGFPC3 containing the human Smad4 cDNA wt or mutated, tagged with GFP. FRTL-5 cells were also transfected with empty vector pEGFPC3. To generate stable transfectants, cells were grown in the presence of $1000 \mu \mathrm{g} / \mathrm{ml}$ geneticin G418 (Invitrogen Life Technologies). After 2 weeks, antibiotic-resistant clones (V1M, Smad4 wt 6M, Smad4 wt 7P, Smad4 C324Y 2M, Smad4 C324Y cl6, and Smad4 C324Y cl8) were selected and expanded in the continuous presence of geneticin $(500 \mu \mathrm{g} / \mathrm{ml})$. Positive clones for GFP expression were identified by screening through western blot analysis using the rabbit polyclonal antibody specific for GFP.

\section{Cell cultures}

The FRTL-5 cells (ATCC \#8305) were kindly provided by Dr Kohn L D (NIH, Bethesda, MD, USA). This cell line, diploid between their 5th and 25th passage, maintains the functional characteristics of iodide uptake, thyroglobulin synthesis, and cyclic nucleotide metabolism over prolonged periods of culture and doubling time of $\sim 36 \mathrm{~h}$ (Ambesi-Impiombato et al. 1980). These cells were grown as previously described (Nicolussi et al. 2003) in Coon's modified Ham's F-12 medium supplemented with $5 \%$ calf serum and $6 \mathrm{H}$ containing TSH $(10 \mathrm{mU} / \mathrm{ml})$, insulin $(10 \mu \mathrm{g} / \mathrm{ml})$, hydrocortisone $\left(10^{-8} \mathrm{M}\right)$, transferrin $(5 \mu \mathrm{g} / \mathrm{ml})$, glycyl-L-histidyl-L-lysine acetate $(10 \mathrm{ng} / \mathrm{ml})$, and somatostatin $(10 \mu \mathrm{g} / \mathrm{ml})$. Clones obtained by stable transfection of the FRTL-5 cells with the expression vector pEGFPC3-Smad4 wt or mutated or with pEGFPC3 empty vector were grown in F-12 Coon's modification medium supplemented with $5 \%$ bovine serum and $6 \mathrm{H}$ mixture in the presence of $500 \mu \mathrm{g} / \mathrm{ml}$ of $\mathrm{G} 418$.
MCF7 and MDA MB468 (Schutte et al. 1996) breast cancer cell lines and HEK293, derived from human embryonic kidney cells, purchased from ATCC (Rockville, MD, USA), were grown in DMEM supplemented with $10 \%$ calf serum.

All cells were maintained in continuous monolayer cultures at $37^{\circ} \mathrm{C}$ and $5 \% \mathrm{CO}_{2}$, expanded up to $70-80 \%$ confluent, treated with human recombinant TGF $\beta 1$ $(10 \mathrm{ng} / \mathrm{ml})$ and then used for the experiments as described below.

\section{Luciferase assays}

These assays were carried out as described previously (Nicolussi et al. 2003, 2006). FRTL-5 and clones were transiently transfected with pCMV5 3TP-Lux and pCMV5- $\beta$ Gal constructs using lipofectin technique following the manufacturer's instructions. MDA MB468 cells were transiently transfected with reporter constructs, pCMV5 3TP-Lux and pCMV5- $\beta$ Gal, with empty vectors, pCMV5 and pEGFPC3, with pEGFPC3-Smad4 wt or with pEGFPC3-Smad4 C324Y or cotransfected with pEGFPC3-Smad4 wt and pEGFPC3-Smad4 C324Y in the stoichiometric ratio Smad4 wt/C324Y 1:1, 1:2, 1:3, 2:1, and 3:1. Moreover, cells were cotransfected with pCMV5 FLAG-Smad2 wt. After transfection, cells were treated or untreated overnight with $10 \mathrm{ng} / \mathrm{ml}$ TGF $\beta 1$ in serum-free medium. Luciferase activities were measured by the luciferase assay system (Promega Corp.) and normalized for transfection efficiency using the $\beta$-galactosidase-expressing control vector. Each result is the mean of three different experiments.

\section{Immunofluorescence}

Immunofluorescence was carried out as described previously (Nicolussi et al. 2006). Cells transiently transfected with pEGFPC3-Smad4 wt or cotransfected with pEGFPC3-Smad4 wt and pEGFPC3-Smad4 C324Y were incubated with or without $10 \mathrm{ng} / \mathrm{ml}$ TGF $\beta 1$ in serum-free medium for 1 and $3 \mathrm{~h}$ and then fixed with $4 \%$ paraformaldehyde/PBS for $30 \mathrm{~min}$, followed by treatment with $0.1 \mathrm{M}$ glycine/PBS for $20 \mathrm{~min}$, and permeabilized with $0.1 \%$ Triton X-100 for an additional $5 \mathrm{~min}$. For detection of $\mathrm{Smad} 2 / 3$, cells were incubated with anti-Smad2/3 antibody (1:50) for $1 \mathrm{~h}$, followed by incubation with Texas-red-conjugated goat anti-mouse IgG (1:100). GFP-Smad4 wt or GFP-Smad4 C324Y was visualized as green fluorescence in overexpressing cells. Nuclei were stained

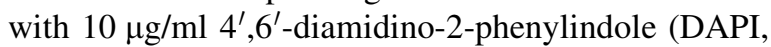
Sigma-Aldrich Co.). Immunofluorescence in FRTL-5 stable clones was carried out as described earlier. 
Fluorescence was observed with a Zeiss Axiophot epifluorescence microscope (Zeiss, Oberkochen, Germany) and photographed at $60 \times$ optical magnification. Each experiment was repeated three times.

\section{Proliferation assays}

The cell proliferation was assessed by cell counting. Briefly, $10 \times 10^{4}$ cells were seeded into $35 \mathrm{~mm}$ plate and allowed to incubate overnight at $37^{\circ} \mathrm{C}$ in a humidified incubator with $5 \% \mathrm{CO}_{2}$. Growth curves were obtained counting the cells at time zero (T0), 24, 48 , and $72 \mathrm{~h}$. Cell growth in the presence and absence of TGF $\beta 1$ was also evaluated. Cell numbers were determined using a hemocytometer both at time zero (T0), to determine the number of cells in the plates before the TGF $\beta 1$ treatment, and after $48 \mathrm{~h}$ with or without $10 \mathrm{ng} / \mathrm{ml}$ TGF $\beta 1$ in serum-free medium. Cells were counted three times by two independent investigators. Inter-observer variation was below 5\%. Values represent mean of triplicate determination \pm s.D. of three experiments and the results were presented also as a percentage of growth inhibition with respect to relative untreated control for each time point.

\section{Soft agar colony formation assay}

To assess the colony formation in soft agar, $1 \times 10^{4}$ cells were resuspended into F-12 Coon's modification medium supplemented with $5 \%$ bovine serum containing $0.4 \%$ agar and plated over a layer of solidified F-12 Coon's modification medium $/ 5 \%$ bovine serum per $0.6 \%$ agar $(2.0 \mathrm{ml})$. After 3 weeks of incubation at $37{ }^{\circ} \mathrm{C}$, the number of large colonies (over $0.125 \mathrm{~mm}$ in diameter) in each plate was counted. Each cell line was tested in triplicate dishes in three independent assays.

\section{Cell morphology}

Stable clones were seeded in $35 \mathrm{~mm}$ plate dishes and culture medium was refreshed at 2-day intervals. Cells were fixed with $4 \%$ paraformaldehyde for $30 \mathrm{~min}$ at $25^{\circ} \mathrm{C}$ and cellular morphology was examined using an Axio Observer inverted microscope (Carl Zeiss, Inc., Oberkochen, Germany) and a Power Shot G5 digital camera (Canon, Inc., Tokyo, Japan) at $5 \times$ optical magnification.

\section{Adhesion assays}

Stock preparations of fibronectin (FN), laminin (LM), or BSA (all provided by Sigma-Aldrich Co.) were diluted in PBS at $20-30 \mu \mathrm{g} / \mathrm{ml}$, and $100 \mu \mathrm{l}$ protein solution was distributed in 96-well flat-bottomed plates
(Costar Corporation, Cambridge, MA, USA). After overnight incubation at $4{ }^{\circ} \mathrm{C}$, the coated wells were washed twice with $\mathrm{PBS}+1 \%$ BSA to remove not immobilized protein. The remaining protein-binding sites were saturated by incubating the plates with PBS $+0.2 \%$ BSA for $1 \mathrm{~h}$ at $37^{\circ} \mathrm{C}$. Cells were detached using EGTA $1 \times($ Sigma-Aldrich Co.), washed and resuspended at $50 \times 10^{3}$ cells $/ \mathrm{ml}$ in serum-free medium containing $0.2 \%$ BSA. Cell suspensions $(100 \mu \mathrm{l})$ were allowed to adhere to $\mathrm{FN}$ - or LM-coated plates for $60 \mathrm{~min}$ at $37{ }^{\circ} \mathrm{C}$ in $5 \% \mathrm{CO}_{2}$. Unattached cells were removed by extensive washing with serum-free medium, while adherent cells were fixed for $10 \mathrm{~min}$ using $3 \%$ paraformaldehyde, stained for $5 \mathrm{~min}$ with $0.5 \%$ crystal violet, washed with water, and then solubilized in $2 \%$ SDS. Cell adhesion was evaluated by reading the optical absorbance (OD) at $620 \mathrm{~nm}$ using an ELISA reader (Titertek Multiscan, Flow Laboratories, High Wycombe, UK).

\section{Migration assays}

Cell migration was measured using a Transwell migration chamber (diameter $5 \mathrm{~mm}$, pore size $8 \mu \mathrm{m}$; Costar Corporation). Cells grown to $70 \%$ confluence in Petri tissue culture dishes were detached using EGTA $1 \times$ (Sigma-Aldrich Co.) and resuspended in serumfree medium containing $0.2 \%$ BSA. TGF $\beta 1(10 \mathrm{ng} / \mathrm{ml})$ treated and untreated cells $\left(30 \times 10^{3}\right.$ cells $\left./ 100 \mu \mathrm{l}\right)$ were seeded in the upper compartment of transwell and allowed to migrate trough the polycarbonate filters using LM $(40 \mu \mathrm{g} / \mathrm{ml}$ in serum-free medium containing $0.2 \%$ BSA) as chemoattractant added in the lower compartment. After $8 \mathrm{~h}$ of incubation at $37^{\circ} \mathrm{C}$, the cells that migrated to the lower side of the membrane were fixed for $5 \mathrm{~min}$ with ethanol, stained for $10 \mathrm{~min}$ with hematoxylin, and counted using an optical microscope. Cells were counted three times by two independent investigators. Inter-observer variation was below $5 \%$. Data are expressed as mean \pm s.D. of the number of migrated cells evaluated in ten different fields obtained from three independent experiments.

\section{Immunoblotting and immunoprecipitation}

Subconfluent cells, transfected or not, were treated or untreated with $10 \mathrm{ng} / \mathrm{ml}$ TGF $\beta 1$ for 30,60 , and $180 \mathrm{~min}$. Protein extracts were obtained using ice-cold TNE extraction buffer $(50 \mathrm{mM}$ Tris- $\mathrm{HCl}$ pH 7.8, $150 \mathrm{mM} \mathrm{NaCl}, 1 \mathrm{mM}$ EDTA, and $1 \%$ Triton X-100) supplemented with $1 \mathrm{mM}$ PMSF, protease and phosphatase cocktail inhibitors. Protein lysates (60 or $80 \mu \mathrm{g}$ ) were subjected to immunoblotting as previously described (Nicolussi et al. 2006) using primary 
antibodies to GFP (1:500), E-cadherin (1:1000), $\mathrm{N}$-cadherin (1:500), and $\beta$-actin (1:5000). Then the membranes were incubated with anti-rabbit (1:50 000) or anti-mouse (1:10 000) HRP-conjugated secondary antibodies. The western blots were revealed by chemiluminescence using the Super Signal Kit from Pierce (Rockford, IL, USA) according to the manufacturer's instructions and visualized on CL-Xposure Film (Pierce). For immunoprecipitation experiments, $1 \mathrm{mg}$ total protein extracted as previously described was precleared with protein-A Sepharose CL-4B (GE Healthcare, Uppsala, Sweden) beads and then immunoprecipitated with anti-GFP polyclonal antibody or monoclonal anti-HA Agarose Conjugate Clone HA-7 (Sigma-Aldrich Co.). Immunocomplexes, aggregated with $50 \mu$ protein-A Sepharose CL-4B or with $30 \mu \mathrm{l}$ monoclonal anti-HA agarose conjugate clone HA-7, were washed four times with $1 \mathrm{ml}$ buffer. The pellets were boiled in Laemmli buffer for $5 \mathrm{~min}$, and the proteins were resolved under reducing conditions by $8 \%$ SDS-PAGE and subjected to immunoblotting as previously described (Nicolussi et al. 2006), using primary antibodies to P-Smad2 (1:500), GFP FL (1:500), and HA (1:500).

Cytosolic and nuclear fractions were obtained as previously described (D'Inzeo et al. 2010) and subjected to immunoblotting using primary antibodies to GFP (1:500), Smad2/3 (1:500), GAPDH (1:5000), and CREB (1:1000).

\section{Wound-healing assay}

Confluent FRTL-5 and clones (35 mm dish) were scratched with a sterile $200 \mu \mathrm{l}$ pipette tip and cellular debris was removed, washing gently. Dishes were plated under a phase-contrast microscope Axio Observer (Zeiss) and photographed to measure the gap distance using the computing Software Axio Vision (Carl Zeiss, Inc.) at the indicated times. Wound distances $(\mu \mathrm{m})$ were measured at nine defined

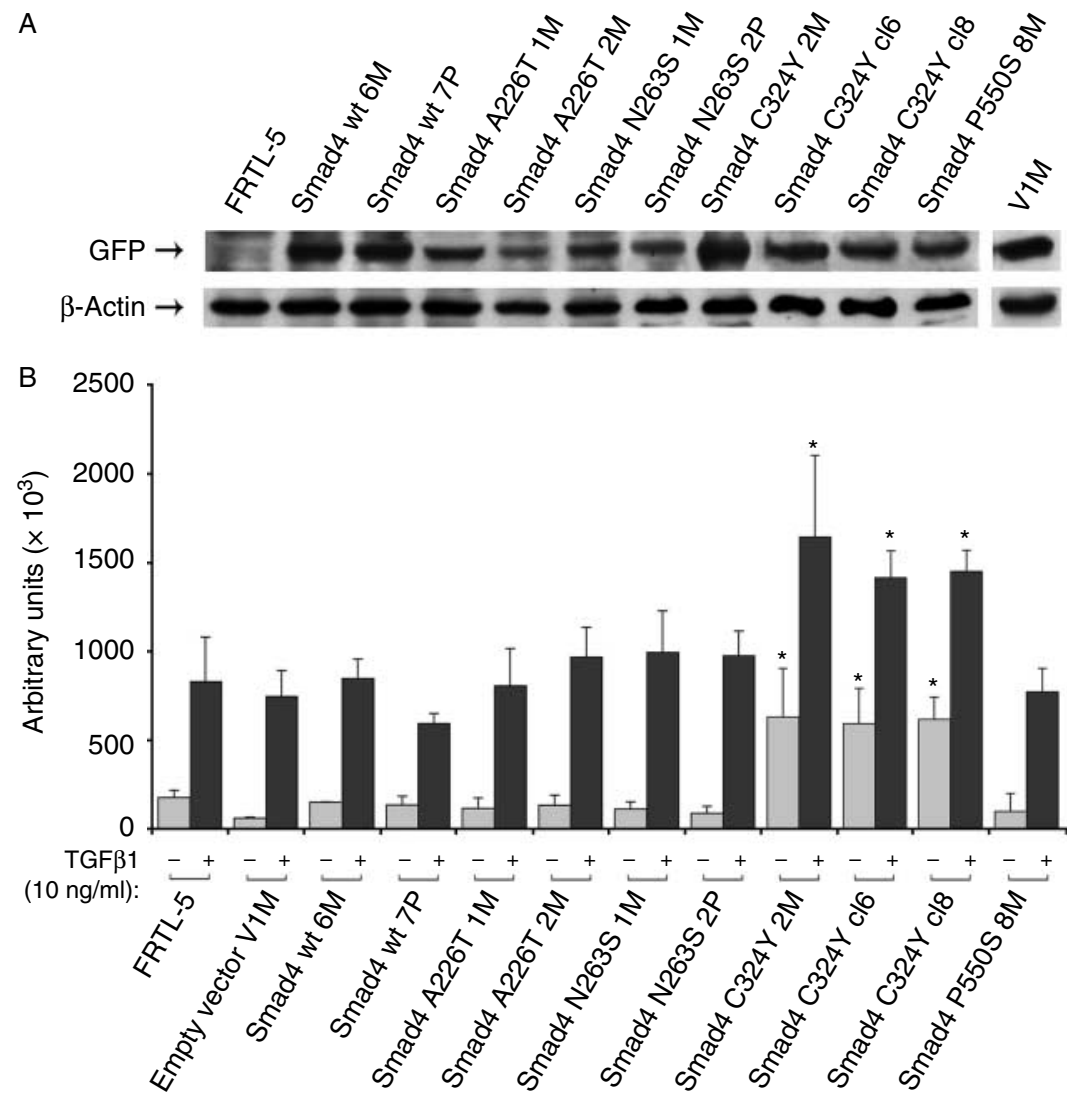

Figure 1 (A) Representative western blot performed by specific antibody anti-GFP on total extracts from FRTL-5 stably transfected cells. (B) Luciferase assays were used to report the activation of 3TP-Lux reporter in FRTL-5 overexpressing Smad4 wt or mutants. The luciferase activity was expressed as arbitrary units. *Indicates a statistical significance $(P<0.05, P$ referred to Student's $t$-test $)$ of FRTL-5 clones overexpressing Smad4 C324Y vs cells transfected with reporter construct or with Smad4 wt. Each result is the mean of three independent experiments in triplicates \pm S.E.M. 


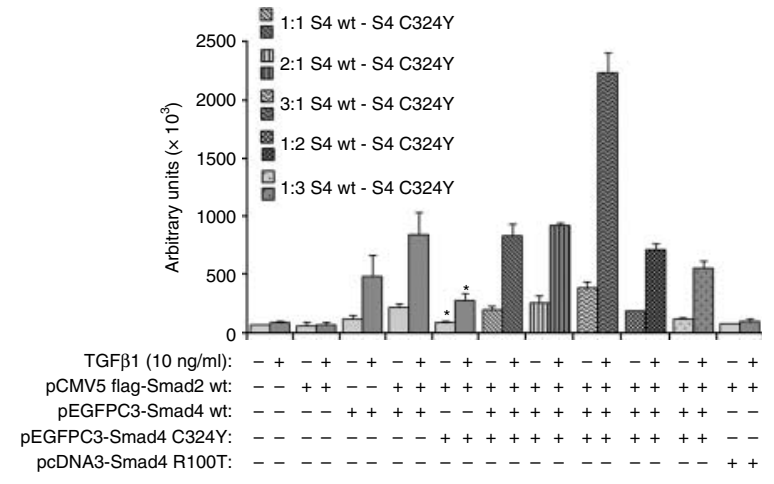

Figure 2 Luciferase assays were used to report the activation of 3TP-Lux reporter, after treatment with $10 \mathrm{ng} / \mathrm{ml} \mathrm{TGF} \beta 1$ for $24 \mathrm{~h}$ in MDA MB468 cells transiently cotransfected with pEGFPC3Smad4 wt or pEGFPC3-Smad4 C324Y and pCMV5 FlagSmad2 wt or cotransfected with Smad4 wt and Smad4 C324Y, increasing the concentrations of Smad4 wt (ratio of Smad4 wt/Smad4 C234Y 1:1, 2:1, or 3:1) or Smad4 C234Y (ratio of Smad4 C324Y/Smad4 wt 1:1, 2:1, or 3:1). The luciferase activity was expressed as arbitrary units. *Indicates a statistical significance $(P<0.05, P$ referred to Student's $t$-test) of MDA MB468 overexpressing Smad4 C324Y vs cells transfected with Smad4 wt. Each result is the mean of three independent experiments in triplicates \pm S.E.M.

points (three parallel marker lines crossed by three parallel wounds) at indicated times. The results were plotted as percentage of the open wound area, starting at $0 \mathrm{~h}(100 \%)$. The experiments were repeated three times.

\section{Statistical analysis}

All statistical analyses were performed by JMP Software purchased by Statistical Discovery SAS Institute (Cary, NC, USA). Data were analyzed by Student's $t$-test $(P<0.05$, statistical significance; $P<0.001$, high statistical significance).

\section{Results}

\section{TGF $\beta$ signaling in FRTL- 5 overexpressing Smad4}

To evaluate whether the mutations Smad4 C324Y, Smad4 A226T, Smad4 N263S, and Smad4 P550S, identified in a group of 56 thyroid tumors of various histotypes (Lazzereschi et al. 2005), could be relevant for thyroid carcinogenesis, FRTL-5 cells were stable transfected with the expression vector pEGFPC3 containing wt or mutated Smad4 cDNAs, tagged with GFP (Fig. 1A). The ability of Smad4 mutants to activate transcriptional responses, both in basal condition and after $24 \mathrm{~h}$ of TGF $\beta 1$ treatment, was examined using the p3TP-Lux reporter construct, transiently transfected in all clones. The p3TP promoter contains three consecutive $12-O$-tetradecanoyl-phorbol-13-acetate response elements, which are involved in the transcriptional responses of several genes to TGF $\beta$, and a portion of the plasminogen activator inhibitor-1 promoter region (de Groot \& Kruijer 1990, Keeton et al. 1991, Wrana et al. 1992).

Our data demonstrated that all clones overexpressing the Smad4 C324Y (C324Y 2M, cl6, and cl8), showed a significant $(P<0.05)$ increase of transcriptional activity already in basal condition with respect to untransfected or Smad4 wt transfected cells. TGF $\beta 1$ treatment significantly $(P<0.05)$ enhanced this response up to 2.5 -fold (Fig. 1B). In contrast, the increase of 3TP-Lux activity, observed in Smad4 A226T, Smad4 N263S, and Smad4 P550S clones after TGF $\beta 1$ treatment, was comparable to that observed in untransfected, empty vector or Smad4 wt transfected cells (Fig. 1B). This result demonstrated that the mutation C324Y was responsible for a significant

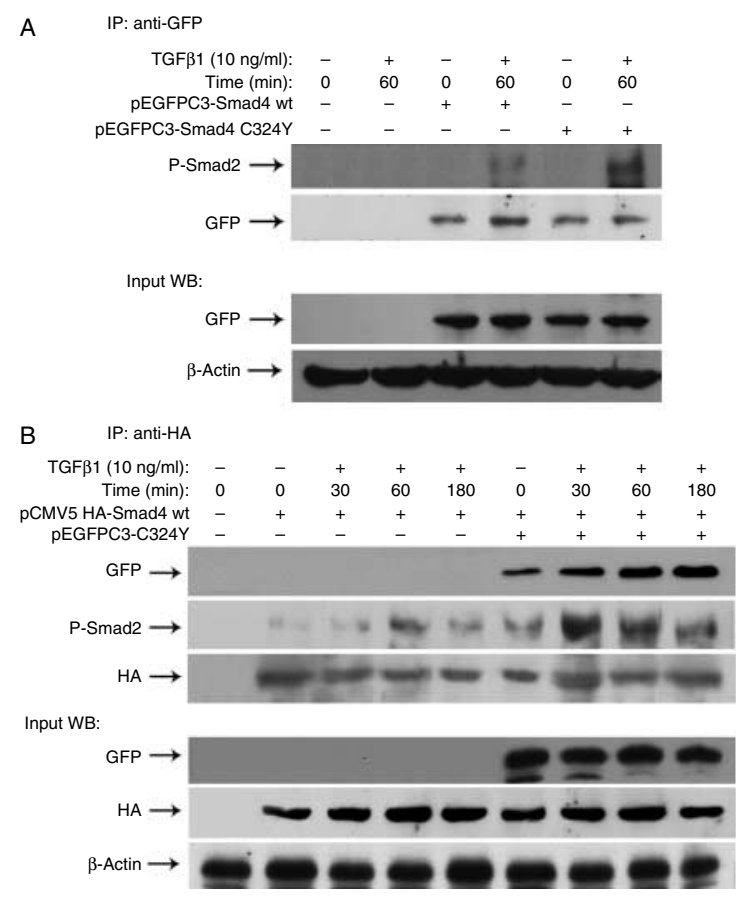

Figure $3(A)$ One milligram of total protein extracted by MDA MB468 transiently transfected with pEGFPC3-Smad4 wt or pEGFPC3-Smad4 C324Y was immunoprecipitated with antiGFP polyclonal antibody and the proteins were resolved under reducing conditions by $8 \%$ SDS-PAGE and subjected to immunoblotting, as previously described in the specific section of Materials and Methods, using primary antibodies to P-Smad2 (1:500) and GFP (1:500). (B) Immunoprecipitation of $1 \mathrm{mg}$ total protein extracted from MDA MB468 transiently transfected with pCMV5 HA-Smad4 wt and/or pEGFPC3-Smad4 C324Y with monoclonal anti-HA agarose conjugate clone HA-7. The proteins were resolved under reducing conditions by $8 \%$ SDS-PAGE and subjected to immunoblotting using primary antibodies to P-Smad2 (1:500), GFP (1:500), and HA (1:500). Transiently transfection and equal loading were verified using primary antibodies to GFP, HA, and $\beta$-actin. 
activation of TGF $\beta$ signaling in FRTL-5 cells. To understand and to well characterize the functionality of Smad4 C324Y mutation, the same experiments were performed in the breast cancer cell line MDA MB468 that lacks endogenous SMAD4 because of homozygous deletion of the SMAD4 gene (Schutte et al. 1996, de Winter et al. 1997). These cells were transiently cotransfected with pEGFPC3-Smad4 wt or pEGFPC3-Smad4 C324Y and pCMV5 Flag-Smad2 wt, with increasing concentration of Smad4 wt or Smad4 C234Y expression vector, respectively (ratio of Smad4 wt/Smad4 C234Y 1:1, 2:1, or 3:1; ratio of Smad4 C324Y/Smad4 wt 1:1, 2:1, or 3:1), and treated or not with $10 \mathrm{ng} / \mathrm{ml}$ TGF $\beta 1$ for $24 \mathrm{~h}$. Dominant negative Smad4 R100T was used as negative control (Morén et al. 2000). Results as seen in Fig. 2, in contrast to those observed in FRTL-5 clones (Fig. 1), showed a significant $(P<0.05)$ reduction in transcriptional activation of 3TP-Lux in cells overexpressing only Smad4 C324Y, with respect to those overexpressing Smad4 wt, both in basal condition and after TGF $\beta 1$ treatment. In the same setting, a strong activation of 3TP-Lux was evident, already when Smad4 wt/Smad4 C324Y ratio was $1: 1$, and was comparable to that of Smad2/Smad4 wt transfected cells. Moreover, this effect was increasing when Smad4 wt/Smad4 C324Y ratio increased. Thus, the data reported show that the simultaneous expression of

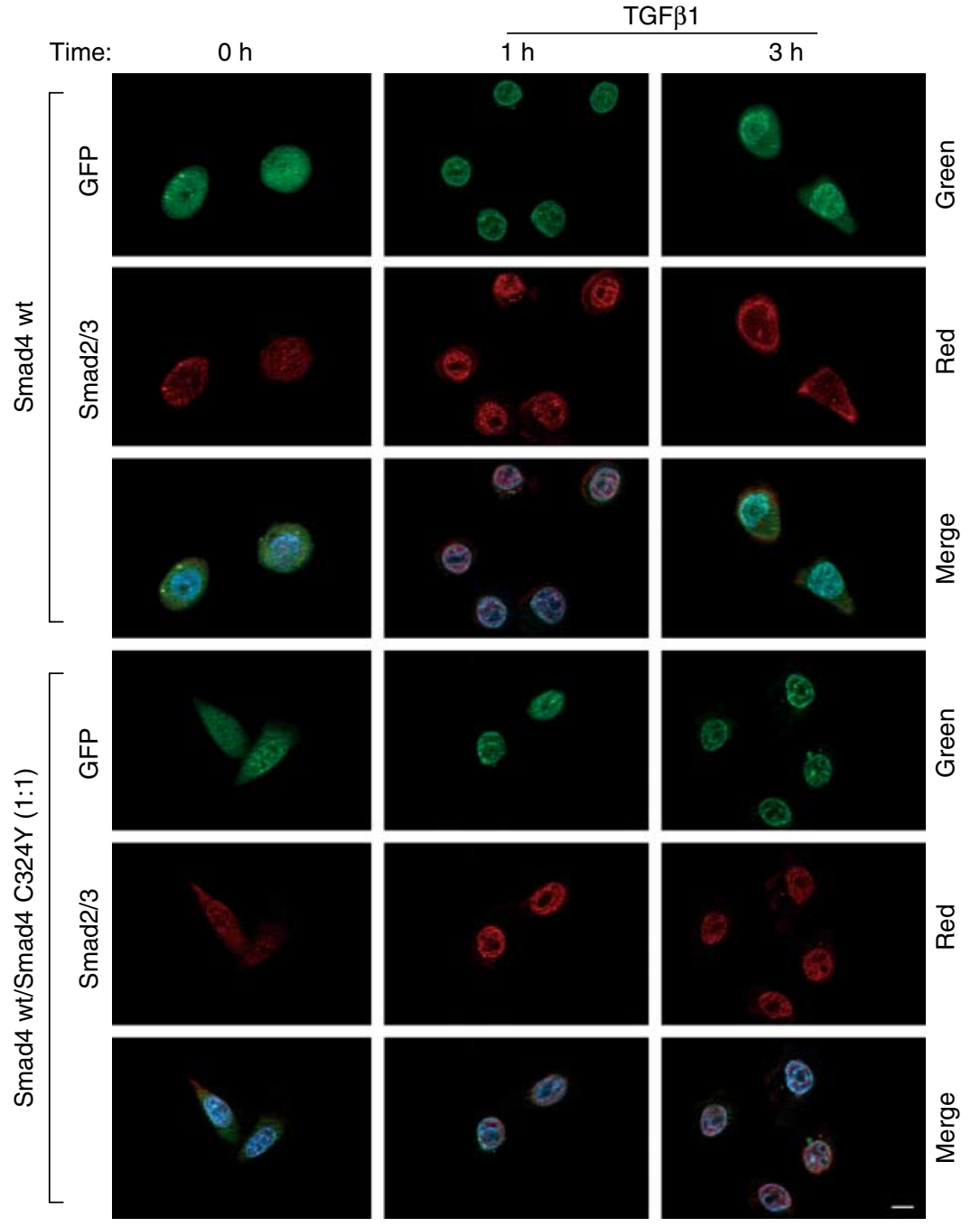

Figure 4 MDA MB468 cells transiently transfected with GFP-tagged Smad4 wt alone or GFP-tagged Smad4 wt/Smad4 C324Y (ratio 1:1) were treated or untreated with $10 \mathrm{ng} / \mathrm{ml} \mathrm{TGF} \beta 1$ for 1 and $3 \mathrm{~h}$, fixed, and immunolabeled using a Smad2/3 monoclonal antibody. Subcellular localization of Smad4 was instead monitored determining the GFP autofluorescence in the transfected cells. Nuclei were counterstained with DAPI. Images are representative of three separate experiments. Scale bar, $20 \mu \mathrm{m}$. 
Smad4 wt and Smad4 C324Y in the cells caused a strong cooperativity between these proteins with a significant increase of TGF $\beta$ signaling.

\section{Properties of the Smad4 C324Y}

To investigate the effect of Smad4 C324Y in the formation of complexes with P-Smad2, immunoprecipitation experiments with anti-GFP antibody were performed by lysates from MDA MB468 transiently transfected with pEGFPC3-Smad4 C324Y or transfected with pEGFPC3-Smad4 wt, untreated or treated with $10 \mathrm{ng} / \mathrm{ml}$ TGF $\beta 1$ for $1 \mathrm{~h}$. The lysates immunoprecipitated were probed with an antibody that recognized P-Smad2. The results in Fig. 3A show that in cells overexpressing Smad4 C324Y, the interaction with P-Smad2 after $1 \mathrm{~h}$ of treatment was stronger compared with that observed in cells overexpressing Smad4 wt. Given the observation that the coexpression of Smad4 wt/Smad4 C324Y in thyroid cells determined an increase of TGF $\beta$ signaling, we tested whether the interaction between the wt and the mutant protein could be responsible for this activation. To this end, we performed a time course immunoprecipitation, comparing lysates from MDA MB468 coexpressing different epitope-tagged Smad4 proteins: pEGFPC3Smad4 C324Y/pCMV5 HA-Smad4 wt or pCMV5 HA-Smad4 wt alone. Consistent with a previous finding that Smad4 proteins exist mainly in an oligomeric state (Hata et al. 1997, Jayaraman \& Massague 2000), our results demonstrate that HA wt and GFP-tagged mutated proteins coimmunoprecipitated, strongly supporting the existence of a homooligomer complex both in the basal state and after TGF $\beta 1$ exposure. Immunoprecipitation of HA-Smad4 wt, after TGF $\beta 1$ treatment, brought down P-Smad2 also (Fig. 3B). The interaction with $\mathrm{P}-\mathrm{Smad} 2$ was already evident after $30 \mathrm{~min}$ of TGF $\beta 1$ treatment. It is interesting to note that the presence of complexes was strongly increased and still evident after $180 \mathrm{~min}$ of treatment in cells coexpressing Smad4 wt and Smad4 C324Y. Similar results were obtained in FRTL-5 clones overexpressing Smad4 C324Y (Supplementary Figure 1, see section on supplementary data given at the end of this article).
A

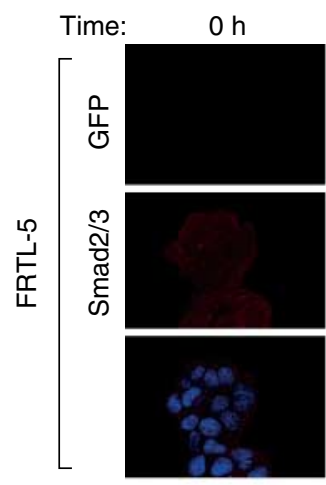

C

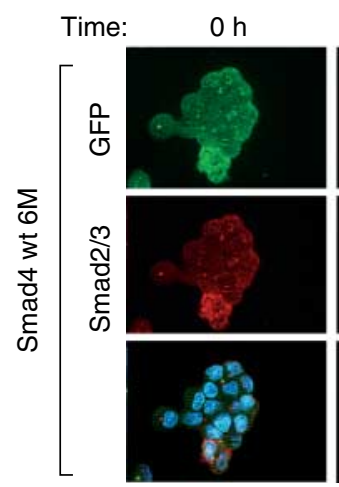

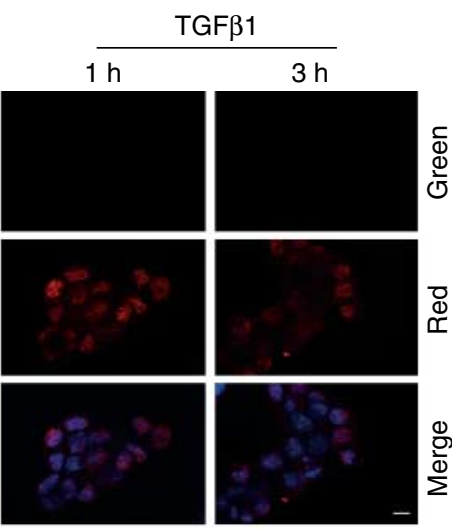

GF $\beta 1$
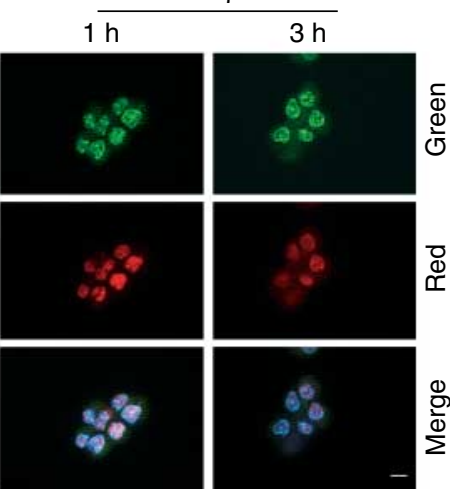

B

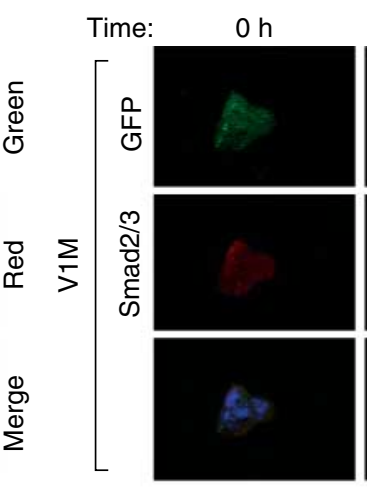

D

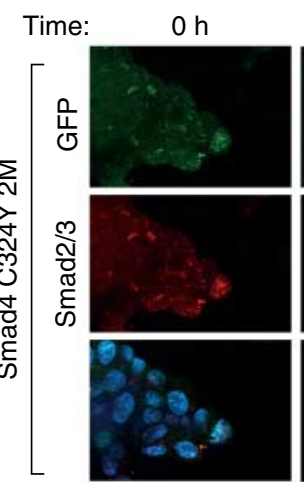

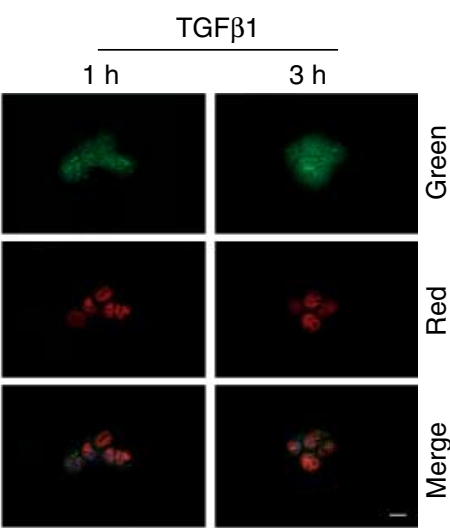

TGF $\beta 1$

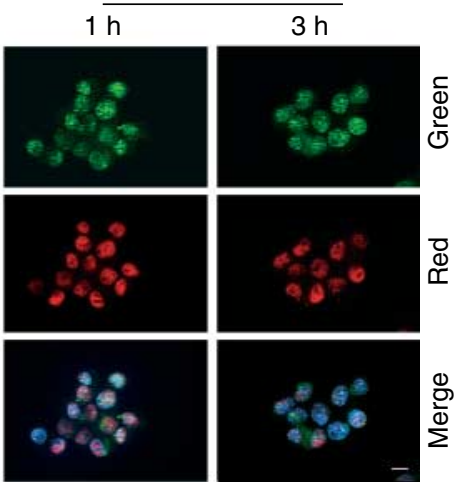

Figure 5 (A-D) FRTL-5 stably transfected clones were treated or untreated with $10 \mathrm{ng} / \mathrm{ml}$ TGF $\beta 1$ for 1 and $3 \mathrm{~h}$, fixed, and immunolabeled using a Smad2/3 monoclonal antibody, monitoring the subcellular localization of Smad4 through GFP autofluorescence. Nuclei were counterstained with DAPI. Images are representative of three separate experiments. Scale bar, $20 \mu \mathrm{m}$. 


\section{Cellular localization of Smad4 C324Y protein}

The subcellular localization of Smad proteins represents a key event for transduction of TGF $\beta$ signal from transmembrane receptors into the nucleus. To determine whether the mutation C324Y could interfere with regular nucleocytoplasmic shuttling of Smad proteins, MDA MB468 cells were transiently transfected with pEGFPC3-Smad4 wt alone or pEGFPC3-Smad4 C324Y/pEGFPC3-Smad4 wt (ratio 1:1) and treated or not with $10 \mathrm{ng} / \mathrm{ml}$ TGF $\beta 1$, for indicated periods of time. Subcellular localization of Smad proteins was monitored by determining the GFP autofluorescence in cells transfected with GFP-tagged Smad4 wt or Smad4 C324Y, treated or untreated, and by indirect immunofluorescence assays using an anti-Smad $2 / 3$ monoclonal antibody. As shown in Fig. 4, the green autofluorescence of the cells transfected with Smad4 wt alone, predominantly cytoplasmic in basal condition, overlapped with the nuclear indirect immunofluorescent red labeling of Smad2/3, mainly after 1 h of TGF $\beta 1$. After 3 h of TGF $\beta 1$ exposure, the localization of GFP-tagged Smad4 wt became nucleocytoplasmic and that of Smad2/3, strongly cytoplasmic. When Smad4 wt and Smad4 C324Y were cotransfected, the overlapping of fluorescence was strongly evident still after $3 \mathrm{~h}$ of TGF $\beta 1$ exposure.

The same experiments were carried out in FRTL-5 stable clones: Smad4 C324Y 2M, coexpressing the mutated protein and endogenous Smad4 wt; Smad4 wt $6 \mathrm{M}$, overexpressing only Smad4 wt; and V1M, transfected with empty vector. FRTL-5 cells were used as control; all clones were treated or not with $10 \mathrm{ng} / \mathrm{ml}$ TGF $\beta 1$ for 1 or $3 \mathrm{~h}$. The results shown in Fig. 5D strongly support that in Smad4 C324Y 2M, the green autofluorescence and the indirect red labeling immunofluorescent $\operatorname{Smad} 2 / 3$ overlapped in the nucleus still after $3 \mathrm{~h}$ of TGF $\beta 1$ treatment, while in Smad4 wt $6 \mathrm{M}$, the overlapping was evident in the nucleus mainly after $1 \mathrm{~h}$ of TGF $\beta 1$, becoming nucleocytoplasmic after $3 \mathrm{~h}$ of TGF $\beta 1$ exposure (Fig. 5C). Fluorescence intensity for nuclear and cytoplasmic areas was measured using the open source Software ImageJ (Wayne Rasbard, NIH, USA), and the ratio of nuclear vs cytoplasmic intensity was plotted (Fig. 6). Western blot, performed on nuclear and cytoplasmic fractions of MDA MB468 transfected with Smad4 wt alone or Smad4 C324Y/Smad4 wt (ratio 1:1; Fig. 7A) and FRTL-5, V1M, Smad4 wt 6M, Smad4 C324Y 2M confirmed that all cells expressing Smad4 C324Y showed a persistent nuclear localization of Smad4 and Smad2/3, still evident after $3 \mathrm{~h}$ of TGF $\beta 1$ treatment (Fig. 7B).

Altogether, these data demonstrate that the expression of Smad4 C324Y protein in the cells was responsible for the formation of transcriptional complexes endowed with increased ability to reside in the nucleus longer than the complexes formed by the Smad4 wt alone. The extended permanence in the nucleus could be responsible for a longer activation of TGF $\beta$ signaling.

\section{Smad4 C324Y expression in the control of thyroid cell proliferation}

To investigate the role of Smad4 C324Y in the control of cell proliferation, FRTL-5, stable clones overexpressing Smad4 C324Y (2M, cl6, and c18), Smad4 wt $6 \mathrm{M}$, and empty vector V1M were counted at T0, 24, 48, and $72 \mathrm{~h}$. All clones overexpressing Smad4 C324Y showed a significant $(P<0.001)$ increase of cell growth with respect to control cells (FRTL-5, V1M, and Smad4 wt 6M) both at 48 and $72 \mathrm{~h}$ (Fig. 8A). Treatment with $10 \mathrm{ng} / \mathrm{ml}$ TGF $\beta 1$ for $48 \mathrm{~h}$ determined a significant $(P<0.001)$ reduction of inhibition of cell proliferation in all Smad4 C324Y clones, with respect to that of untransfected, Smad4 wt, and empty vector
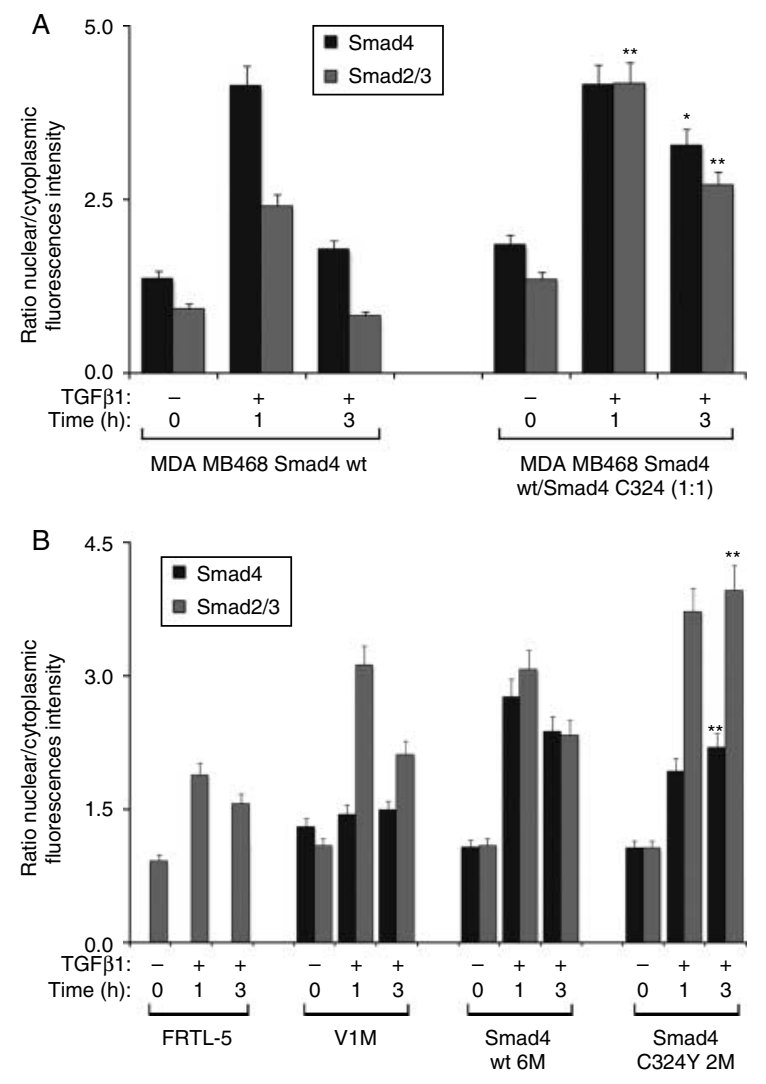

Figure 6 ( $A$ and $B$ ) Quantitative analysis of the ratio of nuclear vs cytoplasmic fluorescence intensity in MDA MB468 transiently transfected with GFP-tagged Smad4 wt alone or GFP-tagged Smad4 wt/Smad4 C324Y (ratio 1:1) and in FRTL-5 stably transfected clones (refer Figs 4 and 5 respectively). ${ }^{\star} P<0.05 ;{ }^{* *} P<0.001$. 
A
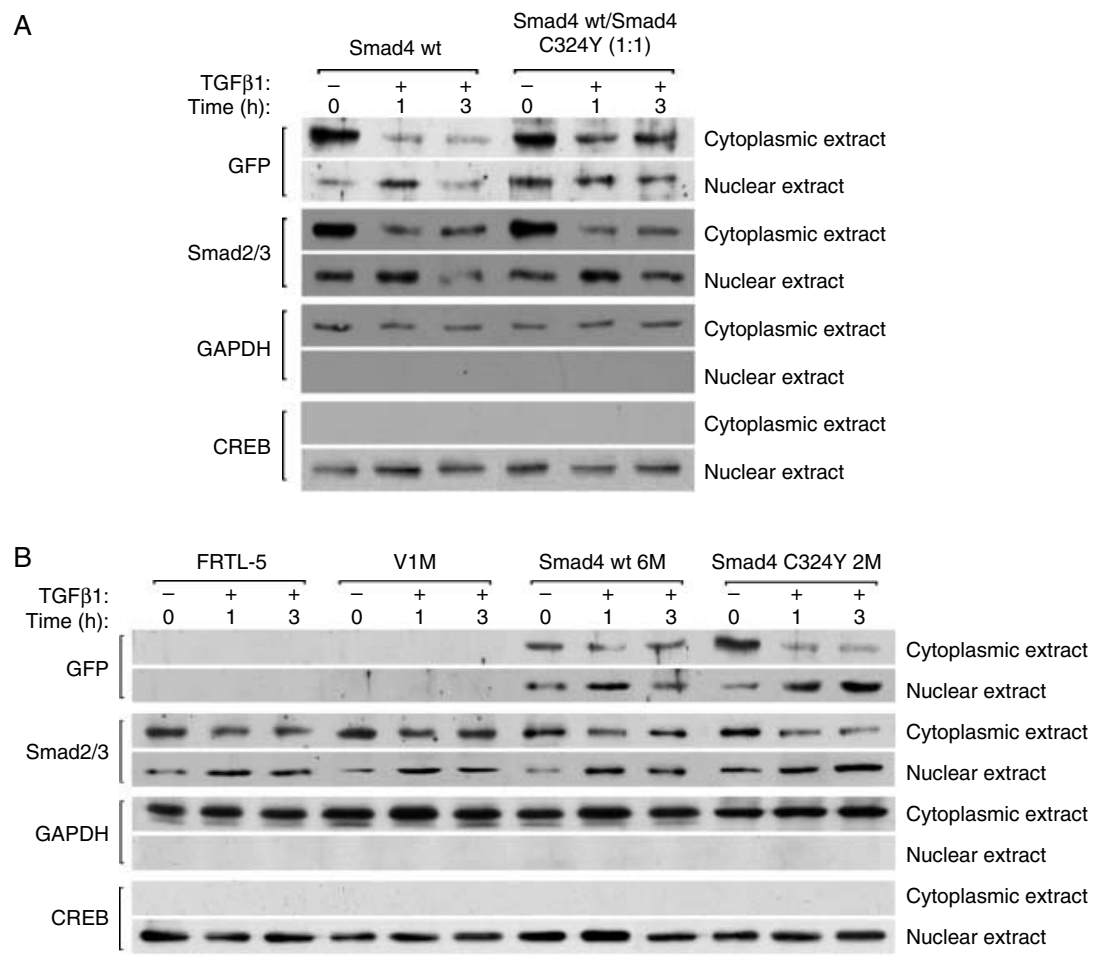

Figure 7 (A) MDA MB468 transiently transfected with GFP-tagged Smad4 wt alone or GFP-tagged Smad4 wt/Smad4 C324Y (ratio $1: 1$ ) and (B) FRTL-5 stably transfected clones, treated with $10 \mathrm{ng} / \mathrm{ml} \mathrm{TGF} \beta 1$ for indicated time periods, were separated into cytosol and nuclear fractions before analysis by immunoblotting with the Smad2/3 (1:500) and GFP (1:500) antibodies. Western blots, performed by antibodies against the GAPDH (1:5000), cytoplasmic protein, and against CREB (1:1000), nuclear protein, indicated that the extracts are virtually free from cross contamination.

transfected cells $(22,24$, and $18 \%$ in $\mathrm{C} 324 \mathrm{Y} 2 \mathrm{M}$, cl6, and cl8, respectively, vs 57\% FRTL-5, 47\% V1M, and $52 \%$ wt 6M; Fig. 8B).

Anchorage-independent growth of cells in soft agar is one of the hallmarks of cellular transformation and uncontrolled cell growth, with normal cells typically not capable of growth in semisolid matrices. To determine whether the increase of TGF $\beta$ signaling, caused by overexpression of Smad4 C324Y in thyroid cells, correlates with an induction in the transformation properties, we compared the ability of Smad4 C324Y clones (C324Y 2M, cl6, and cl8) to grow in soft agar with that of empty vector transfected cells, Smad4 wt clones, or untransfected FRTL-5. The results showed a strong and significant $(P<0.001)$ colony-forming ability in all $\mathrm{C} 324 \mathrm{Y}$ clones with respect to that observed in all control cells, which were completely unable to grow in anchorage-independent conditions (Fig. 9). Lack of responsiveness to TGF $\beta$ antiproliferative effect is a hallmark for the cancer, where TGF $\beta$ and its pathway function as oncosuppressors. Our data demonstrate that Smad4 C324Y mutation expressed in thyroid cells exerted a clear pro-oncogenic function.

\section{Smad4 C324Y expression modifies cellular morphology of thyroid cells}

We then analyzed the possible morphological changes due to overexpression of C324Y mutant form of Smad4. Phase-contrast photomicroscopy of FRTL-5 stably Smad4 transfected clones (wt 6M, wt 7P, C324Y 2M, C324Y cl6, and C324Y cl8) and empty vector clone $(\mathrm{V} 1 \mathrm{M})$ indicates that in the presence of $6 \mathrm{H}$ complete medium, all clones overexpressing Smad4 C324Y present a fibroblast-like appearance compared with V1M or Smad4 wt clones (wt $6 \mathrm{M}$ and wt $7 \mathrm{P}$; Fig. 10). These data indicate that the changes observed in the cell phenotype were due to the Smad4 mutated gene transfected and not due to an indirect action of the transgene used.

\section{Smad4 C324Y in the control of migratory behavior of thyroid cells}

The fibroblast-like appearance observed in C324Y 2M, $\mathrm{C} 324 \mathrm{Y}$ cl6, and $\mathrm{C} 324 \mathrm{Y}$ cl8 clones could state the beginning of epithelial-mesenchymal transition (EMT) process. EMT is essential for organogenesis and is 

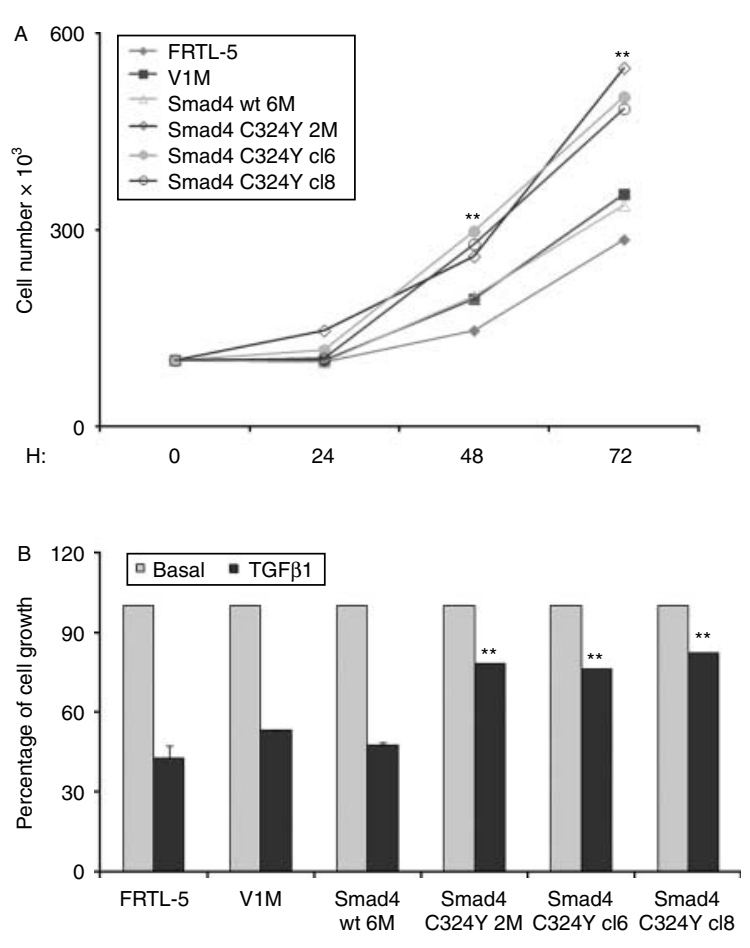

Figure 8 (A) FRTL-5 stably transfected clones were grown in W/O supplemented with $5 \%$ calf serum and six-hormone mixture $(6 \mathrm{H})$ and were counted three times by two independent investigators at T0, 24, 48, and $72 \mathrm{~h}\left({ }^{* *}\right.$ indicate statistical significance (Student's $t$-test) $P<0.001$ of Smad4 C324Y clones vs control cells). (B) Cells were grown in the presence or absence of $10 \mathrm{ng} / \mathrm{ml}$ TGF $\beta 1$ for $48 \mathrm{~h}$ and were counted three times by two independent investigators. Inter-observer variation was below $5 \%$. Values represent mean of triplicate determination \pm s.D. of three experiments and the results were expressed as a percentage of growth inhibition (**indicate statistical significance (Student's $t$-test) $P<0.001$ of Smad4 C324Y clones treated vs control cells treated).

triggered during carcinoma progression to an invasive state. TGF $\beta$ cooperates with signaling pathways, such as Ras and Wnt, to induce EMT (Pardali \& Moustakas 2007, Vincent et al. 2009), but the molecular mechanisms are not yet clear. To determine whether Smad4 C324Y was involved in inducing EMT in thyroid cells, we performed western blot on lysates from all transfected clones using specific $\mathrm{E}$ - or $\mathrm{N}$-cadherin antibodies. MCF7 was used as positive control of E-cadherin and negative control of N-cadherin; instead, HEK293 was used as positive control of $\mathrm{N}$-cadherin and negative control of E-cadherin (Hogan et al. 2004). The results demonstrate that the expression of E-cadherin was dramatically lower in all clones expressing Smad4 C324Y with respect to those transfected with Smad4 wt or empty vector and untransfected FRTL-5. The detectable levels of $\mathrm{N}$-cadherin, observable only in Smad4 C324Y clones (Fig. 11), highlight cadherin switching, confirming that these cells underwent EMT.
Downregulation of E-cadherin has been also associated with reduced cell adhesion and enhanced motility (Yamaguchi et al. 2005). Cell adhesion was evaluated in all clones by plating the cells on FN or LM substrates, leaving the cells to adhere for $1 \mathrm{~h}$. The results show that all clones expressing Smad4 C324Y mutation had a capacity to adhere to the substrates, FN and LM, lower than that of controls FRTL-5, V1M, and Smad4 wt clones, whose adherence to various substrates was comparable (Fig. 12). In particular, the adhesion of C324Y 2M, C324Y cl6 and C324Y c18 to $\mathrm{FN}$ was significantly reduced by $54 \%(P<0.001)$, $37 \%(P<0.05)$ and $36 \%(P<0.05)$ respectively, compared with that of FRTL-5 and by $52 \%$ $(P<0.001), 34 \% \quad(P<0.05)$ and $34 \% \quad(P<0.05)$ respectively, compared to $\mathrm{Smad} 4$ wt clones (Fig. 12A). The capacity to adhere to LM of C324Y clones was significantly reduced compared with FRTL-5 $(56 \% ; P<0.001)$ and Smad4 wt clones (43\%; $P<0.001$; Fig. 12B).

The evaluation of the migratory ability of the clones was carried out in the presence or absence of $10 \mathrm{ng} / \mathrm{ml}$ TGF $\beta 1$, using transwells and allowing the cells to migrate toward the chemoattractant LM for $8 \mathrm{~h}$. Data shown in Fig. 13 demonstrate that clones expressing Smad4 C324Y had a significant $(P<0.001)$ ability to migrate toward LM with respect to all control cells (V1M, wt 6M, wt 7P, and untrasfected FRTL-5).

The ability of Smad4 C324Y clones to migrate was also studied using the wound-healing assay. The cells were grown to confluence in monolayers and their

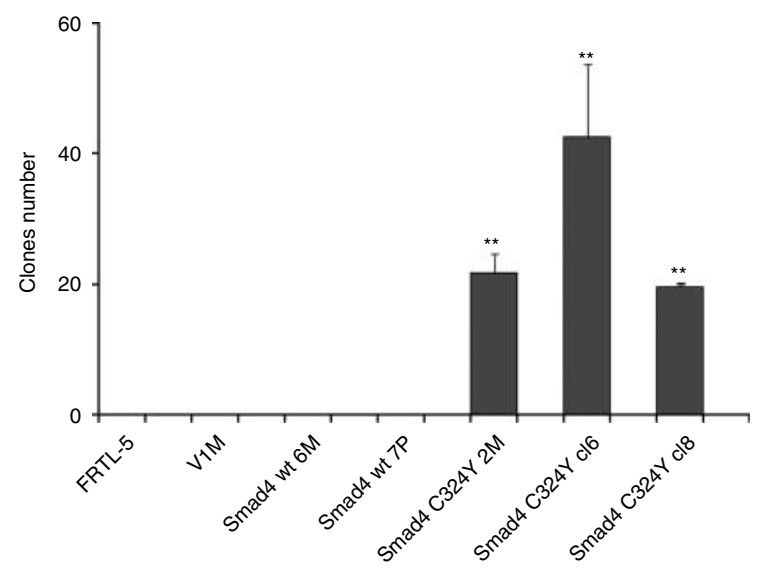

Figure 9 Colony-forming efficiency of FRTL-5 stable clones (V1M, Smad4 wt 6M, Smad4 wt 7P, Smad4 C324Y 2M, Smad4 C324Y cl6, and Smad4 C324Y cl8) and FRTL-5 untransfected cells. Cells $\left(1 \times 10^{4}\right)$ were seeded in soft agar, and after 3 weeks of incubation at $37^{\circ} \mathrm{C}$, colony-forming efficiency was measured as the number of large colonies (over $0.125 \mathrm{~mm}$ in diameter) scored in each plate. Each cell line was tested in triplicate dishes in three independent assays. ${ }^{\star \star} P<0.001$. 

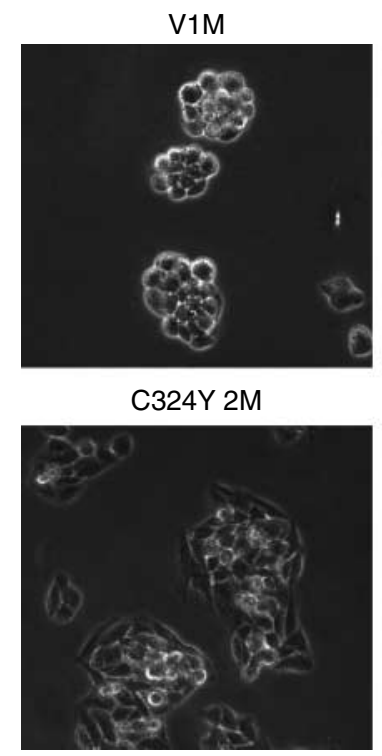

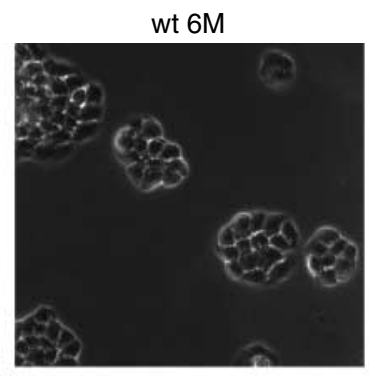

C324Y cl6

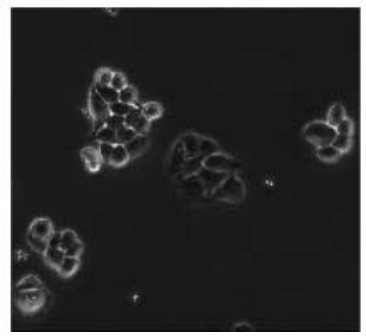

wt 7P

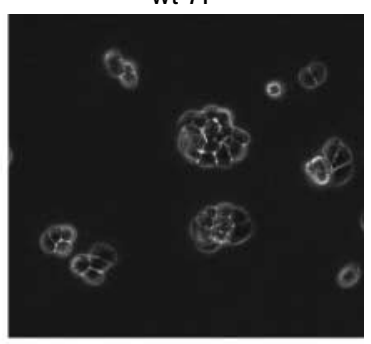

C324Y cl8

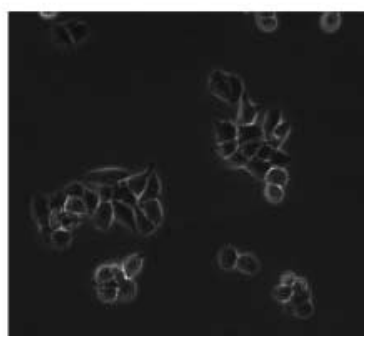

Figure 10 Stable clones were seeded in $35 \mathrm{~mm}$ plate dishes, fixed with $4 \%$ paraformaldehyde for $30 \mathrm{~min}$ at $25^{\circ} \mathrm{C}$, and cellular morphology was examined using an Axio Observer inverted microscope at $5 \times$ optical magnification.

ability to migrate into and across a denuded area of the monolayer was evaluated after $24 \mathrm{~h}$. As shown in Fig. 14, all Smad4 C324Y clones (C324Y 2M, c16, and cl8) had a significant migratory attitude compared with FRTL-5 $(P<0.05)$ and to Smad4 wt clones $(P<0.001)$, which migrated quite slowly. Therefore, all these results suggest that the simultaneous presence of Smad4 wt and Smad4 C324Y could be responsible for the acquisition of an invasive phenotype of thyroid cells.

\section{Discussion}

Many clinical studies highlight the dichotomous role of the TGF $\beta$ pathway in human cancers. Depending on the tumor type and the stage of tumor progression, it can exhibit strong tumor-suppressive or tumor-promoting functions. Smad4 plays a central role in the TGF $\beta$ signal, representing the common mediator which forms complexes, after receptor-induced phosphorylation of R-Smads (Smad2 and Smad3), that are translocated to the nucleus, where they regulate the transcription of responsive genes (Attisano \& Lee-Hoeflich 2001).

The core components of the TGF $\beta$ signaling pathway are mutated or deleted in pancreatic, colon, gastric, and thyroid tumors, shutting down all signaling (Hahn et al. 1996, Thiagalingam et al. 1996, D'Inzeo et al. 2010). However, tumors such as breast cancer, skin cancer, and gliomas exhibit much lower levels of mutations in these core factors and may in fact derive a selective advantage from the TGF $\beta$ pathway
(Padua \& Massagué 2009). This has been traditionally known as the TGF $\beta$ switch in cancer progression. Moreover, TGF $\beta$ is a potent inducer of EMT, first reported in mouse heart formation and palate fusion, in some mammary cell lines, and in mouse models of skin carcinogenesis (Thiery 2003, Derynck \& Akhurst 2007). The acquisition of a mesenchymal phenotype gives the cells increased mobility and invasive properties. This behavior raises the possibility that the EMT process enables cancer cell dissemination (Padua \& Massagué 2009). In immortalized rat thyroid cells overexpressing oncogenic BRAF and in a group of BRAF V600E papillary thyroid carcinomas, it has been demonstrated that a high TGF $\beta /$ Smad activity correlates with local invasion and nodal metastasis (Riesco-Eizaguirre et al. 2009). Knauf et al. (2011) have recently shown that in mouse BRAF transformed

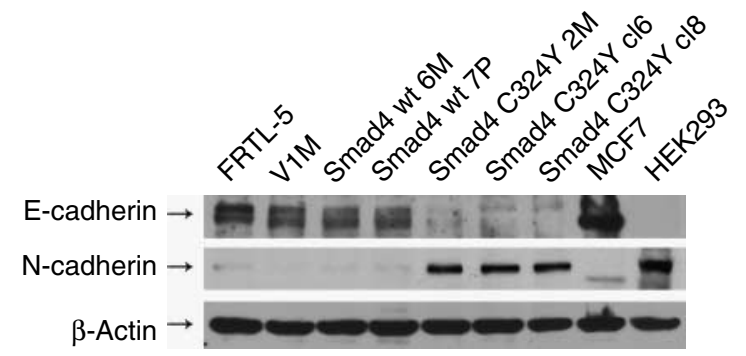

Figure 11 Whole cell extracts (60 $\mu \mathrm{g} / \mathrm{lane})$, extracted as reported in the specific section of Materials and Methods, were analyzed by western blot using antibodies against E-cadherin $(1: 1000)$, N-cadherin (1:500), and $\beta$-actin (1:5000) as equal loading control. 

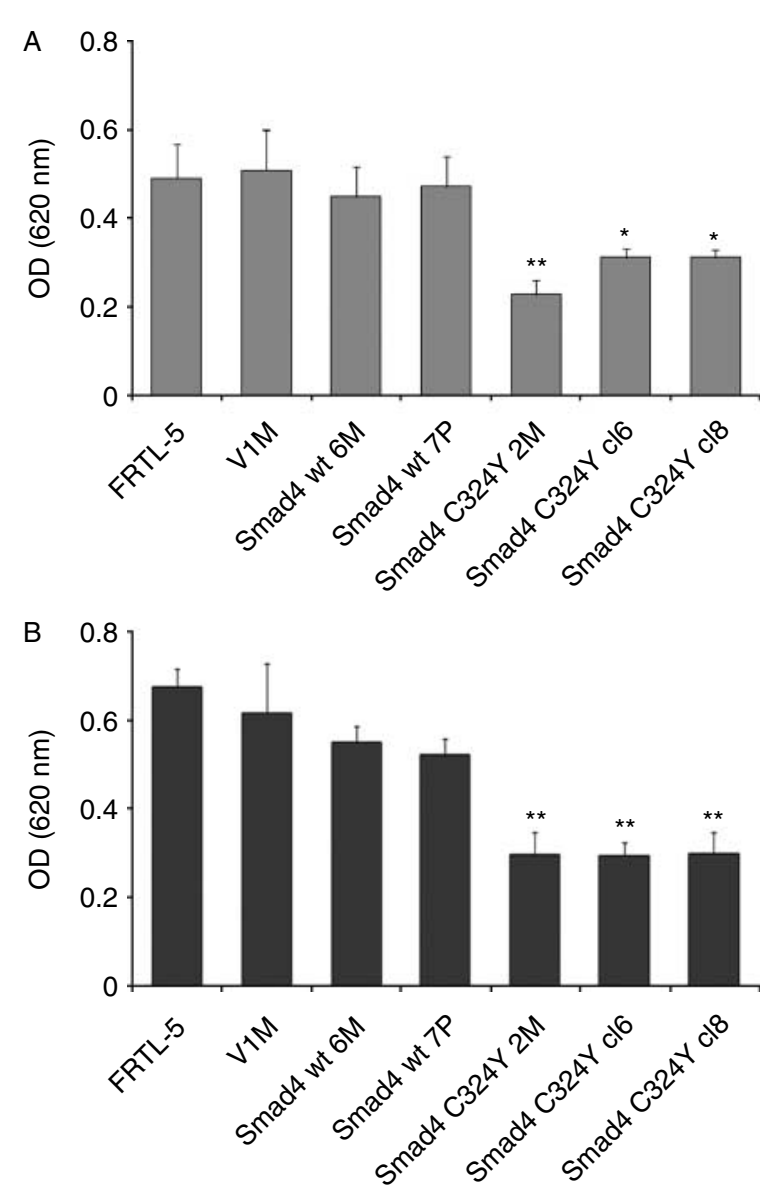

Figure 12 FRTL-5 stable clones were allowed to adhere to FN (panel A) or LM (panel B) precoated wells, fixed in 3\% paraformaldehyde, and stained with crystal violet. Colorimetric reaction was quantified by reading (OD) at $620 \mathrm{~nm}$ using an ELISA reader. Data are presented as mean \pm S.D. of the OD obtained in triplicate determination from at least three independent experiments subtracting the mean of adhesion values obtained on BSA. *Indicates statistical significance $P<0.05$ of clones vs FRTL-5 untransfected cells and Smad4 wt clones. ${ }^{\star} P<0.05 ;{ }^{\star \star} P<0.001$

thyroid cancer cells is, also, required a constitutive activation of the mitogen-activated protein kinase pathway that converges on Smads to modulate TGF $\beta$ transcriptional output. In this study, we have shown that the point mutation $\mathrm{C} 324 \mathrm{Y}$, localized in the MH2 domain of Smad4 protein, stably expressed in FRTL-5 cells, is responsible for the acquisition of transformed feature, as demonstrated by the loss of inhibition of cell proliferation and by the capacity of all clones to grow in anchorage-independent conditions. The stable expression of Smad4 C324Y in thyroid cells determines a significant increase of 3TP-Lux activity, both in basal conditions and after TGF $\beta$ treatment, attesting a strong increase of the signaling. Structural studies support the notion that MH2 domain and part of the linker domain of Smad4 are important for the formation of homomeric (Shi et al. 1997, Jayaraman \& Massagué 2000, Wu et al. 2001) or heterotrimeric complexes (Smad2/Smad2/Smad4, Smad3/Smad3/ Smad4, or Smad3/Smad2/Smad4; Chacko et al. 2004). However, the possibility that other forms of heteromeric Smads assembly can exist in vivo cannot be ruled out. The Smad4 mutation E330A, found to be frequently associated with tumors, is transcriptionally inactive because of abolished TGF $\beta$-dependent oligomerization of Smad4 with Smad3 (Prokova et al. 2007). In contrast, here we demonstrate that a Smad4 mutant, bearing a single point mutation at position C324Y, determines an increase of oligomerization of Smad4 with R-Smads and a lengthening of nuclear localization, responsible for an increase of TGF $\beta$ signaling. Thus, we think that Smad4 mutations arising from amino acid residues 273-552, based on the localization of specific residue, can positively or negatively affect the physical interactions between MH2 subunits of Smad4 and R-Smads. Data demonstrating that $\mathrm{Smad} 4$ proteins exist as trimeric molecules via homomeric interactions of the $\mathrm{MH} 2$ domain (Shi et al. 1997, Chen et al. 2006) let us hypothesize that homo-oligomerization of Smad4 C324Y with Smad4 wt is likely to be the basis for the formation of transcriptional complexes that accumulate into the nucleus. In fact, only when Smad4 C324Y and Smad4

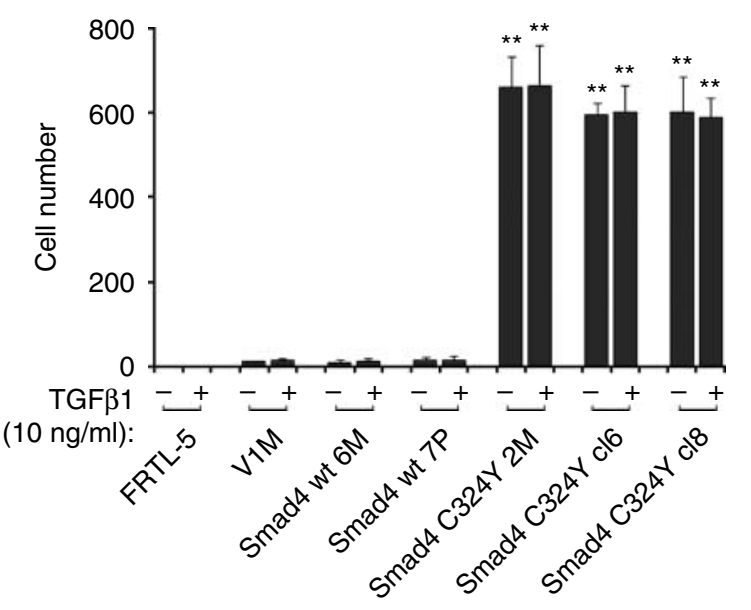

Figure 13 FRTL-5 stable clones were assayed for their ability to migrate through the polycarbonate filters using $\mathrm{LM}(40 \mu \mathrm{g} / \mathrm{ml})$ as chemioattractant. Following $8 \mathrm{~h}$ of incubation, cells were ethanol-fixed and stained with hematoxylin. Data are expressed as mean \pm S.D. of the number of migrated cells evaluated in ten different fields obtained from three independent experiments.

**Indicate statistical significance $P<0.001$, of C324Y clones vs all control cells (FRTL-5 untransfected, stably transfected with empty vector (V1M) or transfected with the wt form of Smad4 $(6 \mathrm{M}, 7 \mathrm{P}))$. 


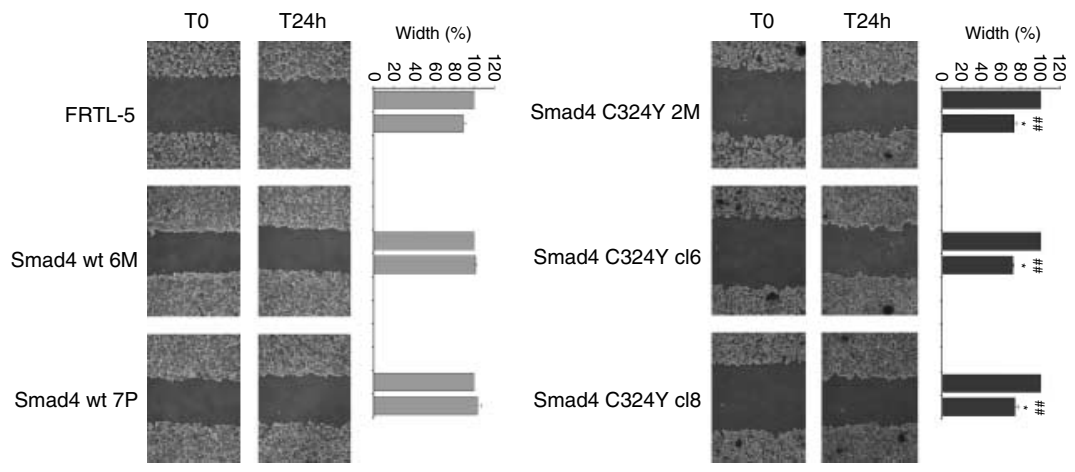

Figure 14 Wound-healing assay was performed in confluent monolayers for $24 \mathrm{~h}$ and the extension of the area colonized by the cells was estimated using Axio Vision, Zeiss Software. *, \#\#Indicate a statistical significance $P<0.05$ and $P<0.001$, respectively, with $P$ referred to Student's $t$-test, of all Smad4 C324Y clones (C324Y 2M, cl6, and cl8) vs FRTL-5 or Smad4 wt.

wt, at different concentrations, are transiently cotransfected in MDA MB468, we observe a strongly activation of TGF $\beta$ signaling. Work over the past few years has emphasized the importance of Smads nucleocytoplasmic shuttling in TGF $\beta$ signaling regulation. The duration of residence in the nucleus of Smad4 is an important event for the response to TGF $\beta$ in the cells (Pierreux et al. 2000, Watanabe et al. 2000, Hill 2009). Many studies demonstrate that the strength and the specificity of signaling correlate with the time that Smad complexes spend in the nucleus; therefore, the activity of Smads is carefully regulated (Gurdon \& Bourillot 2001, Hill 2001, ten Dijke \& Hill 2004, Schmierer et al. 2008). Several mechanisms have been suggested; Smad4 nuclear accumulation is dependent on activated R-Smad binding (Liu et al. 1997, Hoodless et al. 1999, Watanabe et al. 2000) or its interaction with CAN/Nup214 via its MH2 domain (Xu et al. 2002). Whereas the mechanism for the nuclear export of Smad2 remains to be elucidated, the export of Smad4 is mediated by a nuclear export sequence that is found in its linker region and that binds to exportin1/ CRM1 (Pierreux et al. 2000, Watanabe et al. 2000). Nuclear retention is thought to be a key mechanism mediating the accumulation of Smad complexes in the nucleus during signaling (Varelas et al. 2008). The simultaneous expression of Smad4 wt and Smad4 $\mathrm{C} 324 \mathrm{Y}$ in the cells determines a longer nuclear localization of Smad4 C324Y and R-Smads. Although the specific mechanism by which this mutation exerts its action needs further investigation, we think it could play a key role in the control of nucleocytoplasmic shuttling by facilitating the assembly of nuclear transcriptional complexes.

The most striking effect of TGF $\beta$ signaling activation in FRTL-5 clones overexpressing Smad4 $\mathrm{C} 324 \mathrm{Y}$ has been the induction of EMT process.
A fibroblast-like appearance and a strong reduction of the level of E-cadherin, that represent the key events of this process (Miettinen et al. 1994), are evident in all clones examined. The acquisition of a mesenchymal phenotype gives the characteristics of increased cellular motility. Motility of cancer cells seems to be a prerequisite for the metastatic tumor phenotype and chemotaxis may be involved in this process (Gassmann et al. 2004). All Smad4 C324Y clones show a significant reduction of adhesion to substrates such as FN and LM and a strong and significant ability of the cells to migrate. Since the C324Y mutation has been isolated from a nodal metastasis of the papillary thyroid carcinomas, we think that the acquisition of this mutation could represent a late event of thyroid carcinogenesis, which allows the cell to acquire a metastatic phenotype as a response to increased TGF $\beta$ signaling. Taken together with recent evidence that TGF $\beta$ may contribute to the impairment of iodine transport in thyroid cells and it may be engaged during disease progression induced by oncogenic BRAF (Riesco-Eizaguirre et al. 2009, Knauf et al. 2011), we can conclude that TGF $\beta$ signaling plays a key role in thyroid carcinogenesis and can be considered as a new prognostic and therapeutic target for thyroid cancer.

\section{Supplementary data}

This is linked to the online version of the paper at http://dx. doi.org/10.1530/ERC-11-0233.

\section{Declaration of interest}

The authors declare that there is no conflict of interest that could be perceived as prejudicing the impartiality of the research reported. 


\section{Funding}

This study was supported by the Associazione Italiana Ricerca sul Cancro (AIRC).

\section{Acknowledgements}

We thank Prof. Maria Rosaria Torrisi and Dr Francesca Belleudi for providing reagents and for helpful discussion. The authors would also like to thank Mr Daniel Kenton for the careful revisions made. This work is dedicated to the memory of Dr Davide Lazzereschi, MD.

\section{References}

Ambesi-Impiombato FS, Parks L \& Coon HG 1980 Culture of hormone dependent functional epithelial cells from rat thyroids. PNAS 77 3455-3459. (doi:10.1073/pnas.77.6.3455)

Attisano L \& Lee-Hoeflich ST 2001 The Smads. Genome Biology 2 reviews30101-reviews30108. (doi:10.1186/gb2001-2-8-reviews3010)

Blobe GC, Schiemann WP \& Lodish HF 2000 Role of transforming growth factor beta in human disease. New England Journal of Medicine 342 1350-1358. (doi:10. 1056/NEJM200005043421807)

Bornstein S, White R, Malkoski S, Oka M, Han G, Cleaver T, Reh D, Andersen P, Gross N, Olson S et al. 2009 Smad4 loss in mice causes spontaneous head and neck cancer with increased genomic instability and inflammation. Journal of Clinical Investigation 119 3408-3419. (doi:10.1172/JCI38854)

Chacko BM, Qin BY, Tiwari A, Shi G, Lam S, Hayward LJ, De Caestecker M \& Lin K 2004 Structural basis of heteromeric smad protein assembly in TGF-beta signaling. Molecular Cell 15 813-823. (doi:10.1016/j.molcel. 2004.07.016)

Chen Y, Yee D \& Magnuson T 2006 A novel mouse Smad4 mutation reduces protein stability and wild-type protein levels. Mammalian Genome 17 211-219. (doi:10.1007/ s00335-005-0074-3)

Derynck R \& Akhurst RJ 2007 Differentiation plasticity regulated by TGF-beta family proteins in development and disease. Nature Cell Biology 9 1000-1004. (doi:10. 1038/ncb434)

ten Dijke P \& Hill CS 2004 New insights into TGF-betaSmad signalling. Trends in Biochemical Sciences 29 265-273. (doi:10.1016/j.tibs.2004.03.008)

D'Inzeo S, Nicolussi A, Ricci A, Mancini P, Porcellini A, Nardi F \& Coppa A 2010 Role of reduced expression of SMAD4 in papillary thyroid carcinoma. Journal of Molecular Endocrinology 45 229-244. (doi:10.1677/ JME-10-0044)

Gassmann P, Enns A \& Haier J 2004 Role of tumor cell adhesion and migration in organ-specific metastasis formation. Onkologie 27 577-582. (doi:10.1159/ 000081343)

de Groot RP \& Kruijer W 1990 Transcriptional activation by TGF beta 1 mediated by the dyad symmetry element
(DSE) and the TPA responsive element (TRE). Biochemical and Biophysical Research Communications 168 1074-1081. (doi:10.1016/0006-291X(90)91139-J)

Gurdon JB \& Bourillot PY 2001 Morphogen gradient interpretation. Nature 413 797-803. (doi:10.1038/ 35101500)

Hahn SA, Schutte M, Hoque AT, Moskaluk CA, da Costa LT, Rozenblum E, Weinstein CL, Fischer A, Yeo CJ, Hruban RH et al. 1996 DPC4, a candidate tumor suppressor gene at human chromosome 18q21.1. Science 271 350-353. (doi:10.1126/science.271.5247.350)

Hata A, Lo RS, Wotton D, Lagna G \& Massagué J 1997 Mutations increasing autoinhibition inactivate tumour suppressors Smad2 and Smad4. Nature 388 82-87. (doi:10.1038/40424)

Heldin CH, Miyazono K \& ten Dijke P 1997 TGF-beta signalling from cell membrane to nucleus through SMAD proteins. Nature 390 465-471. (doi:10.1038/37284)

Hill CS 2001 TGF-beta signalling pathways in early Xenopus development. Current Opinion in Genetics \& Development 11 533-540. (doi:10.1016/S0959437X(00)00229-X)

Hill CS 2009 Nucleocytoplasmic shuttling of Smad proteins. Cell Research 19 36-46. (doi:10.1038/cr.2008.325)

Hogan C, Serpente N, Cogram P, Hosking CR, Bialucha CU, Feller SM, Braga VM, Birchmeier W \& Fujita Y 2004 Rap1 regulates the formation of E-cadherin-based cellcell contacts. Molecular and Cellular Biology 24 6690-6700. (doi:10.1128/MCB.24.15.6690-6700.2004)

Hoodless PA, Tsukazaki T, Nishimatsu S, Attisano L, Wrana JL \& Thomsen GH 1999 Dominant negative Smad2 mutants inhibit activin/Vg1 signaling and disrupt axis formation in Xenopus. Developmental Biology 207 364-379. (doi:10.1006/dbio.1998.9168)

Iacobuzio-Donahue CA, Song J, Parmiagiani G, Yeo CJ, Hruban RH \& Kern SE 2004 Missense mutations of MADH4: characterization of the mutational hot spot and functional consequences in human tumors. Clinical Cancer Research 10 1597-1604. (doi:10.1158/10780432.CCR-1121-3)

Ikushima H \& Miyazono K 2010 TGFbeta signalling: a complex web in cancer progression. Nature Reviews. Cancer 10 415-424. (doi:10.1038/nrc2853)

Jayaraman L \& Massague J 2000 Distinct oligomeric states of SMAD proteins in the transforming growth factor-beta pathway. Journal of Biological Chemistry 275 40710-40717. (doi:10.1074/jbc.M005799200)

Keeton MR, Curriden SA, van Zonneveld AJ \& Loskutoff DJ 1991 Identification of regulatory sequences in the type 1 plasminogen activator inhibitor gene responsive to transforming growth factor beta. Journal of Biological Chemistry 266 23048-23052.

Knauf JA, Sartor MA, Medvedovic M, Lundsmith E, Ryder M, Salzano M, Nikiforov YE, Giordano TJ, Ghossein RA \& Fagin JA 2011 Progression of BRAF-induced thyroid cancer is associated with epithelial-mesenchymal 
transition requiring concomitant MAP kinase and TGF $\beta$ signaling. Oncogene 30 3153-3162. (doi:10.1038/onc. 2011.44)

Kogai T, Sajid-Crockett S, Newmarch LS, Liu YY \& Brent GA 2008 Phosphoinositide-3-kinase inhibition induces sodium/iodide symporter expression in rat thyroid cells and human papillary thyroid cancer cells. Journal of Endocrinology 199 243-252. (doi:10.1677/JOE-08-0333)

Lazzereschi D, Nardi F, Turco A, Ottini L, D’Amico C, Mariani-Costantini R, Gulino A \& Coppa A 2005 A complex pattern of mutations and abnormal splicing of Smad4 is present in thyroid tumours. Oncogene $\mathbf{2 4}$ 5344-5354. (doi:10.1038/sj.onc.1208603)

Liu F, Pouponnot C \& Massagué J 1997 Dual role of the Smad4/DPC4 tumor suppressor in TGFbeta-inducible transcriptional complexes. Genes and Development 11 3157-3167. (doi:10.1101/gad.11.23.3157)

Massagué J 1998 TGF-beta signal transduction. Annual Review of Biochemistry 67 753-791. (doi:10.1146/ annurev.biochem.67.1.753)

Massagué J \& Gomis RR 2006 The logic of TGFbeta signaling. FEBS Letters 580 2811-2820. (doi:10.1016/j. febslet.2006.04.033)

Massagué J, Seoane J \& Wotton D 2005 Smad transcription factors. Genes and Development 19 2783-2810. (doi:10. 1101/gad.1350705)

Miettinen PJ, Ebner R, Lopez AR \& Derynck R 1994 TGFbeta induced transdifferentiation of mammary epithelial cells to mesenchymal cells: involvement of type I receptors. Journal of Cell Biology 127 2021-2036. (doi:10.1083/jcb.127.6.2021)

Miyaki M, Iijima T, Konishi M, Sakai K, Ishii A, Yasuno M, Hishima T, Koike M, Shitara N, Iwama T et al. 1999 Higher frequency of Smad4 gene mutation in human colorectal cancer with distant metastasis. Oncogene $\mathbf{1 8}$ 3098-3103. (doi:10.1038/sj.onc.1202642)

Morén A, Itoh S, Moustakas A, Dijke P \& Heldin CH 2000 Functional consequences of tumorigenic missense mutations in the amino-terminal domain of Smad4. Oncogene 19 4396-4404. (doi:10.1038/sj.onc.1203798)

Nicolussi A, D'Inzeo S, Santulli M, Colletta G \& Coppa A 2003 TGF-beta control of rat thyroid follicular cells differentiation. Molecular and Cellular Endocrinology 207 1-11. (doi:10.1016/S0303-7207(03)00238-7)

Nicolussi A, D’Inzeo S, Gismondi A \& Coppa A 2006 Reduction of invasive potential in K-ras-transformed thyroid cells by restoring of TGF-beta pathway. Clinical and Experimental Metastasis 23 237-248. (doi:10.1007/ s10585-006-9023-0)

Padua D \& Massagué J 2009 Roles of TGFbeta in metastasis. Cell Research 19 89-102. (doi:10.1038/cr.2008.316)

Pang XP, Hershman JM, Chung M \& Pekary AE 1989 Characterization of tumor necrosis factor-alpha receptors in human and rat thyroid cells and regulation of the receptors by thyrotropin. Endocrinology 125 1783-1788. (doi:10.1210/endo-125-4-1783)
Pardali K \& Moustakas A 2007 Actions of TGF-beta as tumor suppressor and pro-metastatic factor in human cancer. Biochimica et Biophysica Acta 1775 21-62.

Pierreux CE, Nicolás FJ \& Hill CS 2000 Transforming growth factor beta-independent shuttling of Smad4 between the cytoplasm and nucleus. Molecular and Cellular Biology 20 9041-9054. (doi:10.1128/MCB.20. 23.9041-9054.2000)

Pomérance M, Quillard J, Chantoux F, Young J \& Blondeau JP 2006 High-level expression, activation, and subcellular localization of p38-MAP kinase in thyroid neoplasms. Journal of Pathology 209 298-306. (doi:10. 1002/path.1975)

Prokova V, Mavridou S, Papakosta P, Petratos K \& Kardassis D 2007 Novel mutations in Smad proteins that inhibit signaling by the transforming growth factor beta in mammalian cells. Biochemistry 46 13775-13786. (doi:10. 1021/bi701540u)

Riesco-Eizaguirre G, Rodríguez I, De la Vieja A, Costamagna E, Carrasco N, Nistal M \& Santisteban P 2009 The BRAFV600E oncogene induces transforming growth factor beta secretion leading to sodium iodide symporter repression and increased malignancy in thyroid cancer. Cancer Research 69 8317-8325. (doi:10.1158/ 0008-5472.CAN-09-1248)

Schmierer B, Tournier AL, Bates PA \& Hill CS 2008 Mathematical modeling identifies Smad nucleocytoplasmic shuttling as a dynamic signal-interpreting system. PNAS 105 6608-6613. (doi:10.1073/pnas.0710134105)

Schutte M, Hruban RH, Hedrick L, Cho KR, Nadasdy GM, Weinstein CL, Bova GS, Isaacs WB, Cairns P, Nawroz H et al. 1996 DPC4 gene in various tumor types. Cancer Research 56 2527-2530.

Shi Y 2001 Structural insights on Smad function in TGFbeta signaling. BioEssays 23 223-232. (doi:10.1002/15211878(200103)23:3<223::AID-BIES1032>3.0.CO;2-U)

Shi Y, Hata A, Lo RS, Massagué J \& Pavletich NP 1997 A structural basis for mutational inactivation of the tumour suppressor Smad4. Nature 388 87-93. (doi:10.1038/ 40431)

Shimura H, Suzuki H, Miyazaki A, Furuya F, Ohta K, Haraguchi K, Endo T \& Onaya T 2001 Transcriptional activation of the thyroglobulin promoter directing suicide gene expression by thyroid transcription factor-1 in thyroid cancer cells. Cancer Research 61 3640-3646.

Thiagalingam S, Lengauer C, Leach FS, Schutte M, Hahn SA, Overhauser J, Willson JK, Markowitz S, Hamilton SR, Kern SE et al. 1996 Evaluation of candidate tumour suppressor genes on chromosome 18 in colorectal cancers. Nature Genetics 13 343-346. (doi:10.1038/ng0796-343)

Thiery JP 2003 Epithelial-mesenchymal transitions in development and pathologies. Current Opinion in Cell Biology 15 740-746. (doi:10.1016/j.ceb.2003.10.006)

Varelas X, Sakuma R, Samavarchi-Tehrani P, Peerani R, Rao BM, Dembowy J, Yaffe MB, Zandstra PW \& Wrana JL 2008 TAZ controls Smad nucleocytoplasmic 
shuttling and regulates human embryonic stem-cell selfrenewal. Nature Cell Biology 10 837-848. (doi:10.1038/ ncb1748)

Vincent T, Neve EP, Johnson JR, Kukalev A, Rojo F, Albanell J, Pietras K, Virtanen I, Philipson L, Leopold PL et al. 2009 A SNAIL1-SMAD3/4 transcriptional repressor complex promotes TGF-beta mediated epithelialmesenchymal transition. Nature Cell Biology 11 943-950. (doi:10.1038/ncb1905)

Visconti R, Federico A, Coppola V, Pentimalli F, Berlingieri MT, Pallante P, Kruhoffer M, Orntoft TF \& Fusco A 2007 Transcriptional profile of Ki-Ras-induced transformation of thyroid cells. Cancer Investigation $\mathbf{2 5}$ 256-266. (doi:10.1080/07357900701206406)

Watanabe M, Masuyama N, Fukuda M \& Nishida E 2000 Regulation of intracellular dynamics of Smad4 by its leucine-rich nuclear export signal. EMBO Reports 1 176-182. (doi:10.1093/embo-reports/kvd029)

Wikström P, Stattin P, Franck-Lissbrant I, Damber JE \& Bergh A 1998 Transforming growth factor beta1 is associated with angiogenesis, metastasis, and poor clinical outcome in prostate cancer. Prostate 37 19-29. (doi:10.1002/(SICI)1097-0045(19980915)37:1 < 19::AID-PROS4>3.0.CO;2-3)

de Winter JP, Roelen BA, ten Dijke P, van der Burg B \& van den Eijnden-van Raaij AJ 1997 DPC4 (SMAD4) mediates transforming growth factor-beta1 (TGF-beta1) induced growth inhibition and transcriptional response in breast tumour cells. Oncogene 14 1891-1899. (doi:10.1038/sj. onc.1201017)

Wotton D, Lo RS, Lee S \& Massagué J 1999 A Smad transcriptional corepressor. Cell 97 29-39. (doi:10.1016/ S0092-8674(00)80712-6)

Wrana JL, Attisano L, Carcamo J, Zentella A, Doody J, Laiho M, Wang XF \& Massagué J 1992 TGFbeta signals through a heteromeric protein kinase receptor complex. Cell 71 1003-1014. (doi:10.1016/0092-8674(92)90395-S)

Wu JW, Fairman R, Penry J \& Shi Y 2001 Formation of a stable heterodimer between Smad2 and Smad4. Journal of Biological Chemistry 276 20688-20694. (doi:10.1074/ jbc.M100174200)

Xu L, Kang Y, Cöl S \& Massagué J 2002 Smad2 nucleocytoplasmic shuttling by nucleoporins CAN/Nup214 and Nup153 feeds TGFbeta signaling complexes in the cytoplasm and nucleus. Molecular Cell 10 271-282. (doi:10.1016/S1097-2765(02)00586-5)

Yamaguchi H, Wyckoff J \& Condeelis J 2005 Cell migration in tumors. Current Opinion in Cell Biology 17 559-564. (doi:10.1016/j.ceb.2005.08.002)

Received in final form 21 October 2011

Accepted 22 November 2011

Made available online as an Accepted Preprint 22 November 2011 